\title{
Evolution of the climate in the next million years: A reduced- complexity model for glacial cycles and impact of anthropogenic $\mathrm{CO}_{2}$ emissions
}

5 Stefanie Talento ${ }^{1}$, Andrey Ganopolski ${ }^{1}$

${ }^{1}$ Potsdam Institute for Climate Impact Research, Potsdam, 14473, Germany

Correspondence to: Stefanie Talento (talento@pik-potsdam.de)

\begin{abstract}
We propose a reduced-complexity process-based model for the long-term evolution of the global ice volume, atmospheric $\mathrm{CO}_{2}$ concentration and global mean temperature. The model only external forcings are the orbital forcing and anthropogenic $\mathrm{CO}_{2}$ cumulative emissions. The model consists of a system of three coupled non-linear differential equations, representing physical mechanisms relevant for the evolution of the Climate - Ice Sheets - Carbon cycle System in timescales longer than thousands of years. The model is successful in reproducing the glacial-interglacial cycles of the last $800 \mathrm{kyr}$, in good agreement with the timing and amplitude of paleorecord fluctuations, with the best correlation between modelled and paleo global ice volume of 0.86 . Using different model realisations, we produce a probabilistic forecast of the evolution of the

15 Earth system over the next 1 million years under natural and several fossil-fuel $\mathrm{CO}_{2}$ release scenarios. In the natural scenario, the model assigns high probability of occurrence of long interglacials in the periods between present and $120 \mathrm{kyr}$ after present, and between $400 \mathrm{kyr}$ and $500 \mathrm{kyr}$ after present. The next glacial inception is most likely to occur $\sim 50 \mathrm{kyr}$ after present with full glacial conditions developing $\sim 90 \mathrm{kyr}$ after present. The model shows that even already achieved cumulative $\mathrm{CO}_{2}$ anthropogenic emissions (500 PgC) are capable of affecting climate evolution for up to half million years, indicating that the

20 beginning of the next glaciation is highly unlikely in the next 120 kyr. High cumulative anthropogenic $\mathrm{CO}_{2}$ emissions (3000 PgC or higher), which could potentially be achieved in the next two to three centuries if humanity does not curb the usage of fossil-fuels, will most likely provoke Northern Hemisphere landmass ice-free conditions throughout the next half million years, postponing the natural occurrence of the next glacial inception to $600 \mathrm{kyr}$ after present or later.
\end{abstract}

\section{Introduction}

25 Numerous paleoclimate records show that climate of the last 2.7 Myr is characterized by persistent alternations of glacial and interglacial episodes. The last $800 \mathrm{kyr}$ were dominated by strongly asymmetric glacial cycles with average periodicity of about 100 kyr, a rather slow glacial build-up and much more rapid deglaciations (Hays et al. 1976; Lisiecki and Raymo, 2005). Antarctic ice core records also show that atmospheric Carbon dioxide $\left(\mathrm{CO}_{2}\right)$ concentration fluctuated nearly synchronously with the global ice volume, and that $\mathrm{CO}_{2}$ concentration during glacial times was up to $100 \mathrm{ppm}$ lower than during preindustrial time (Petit et al., 1999, Lüthi et al., 2008).

The astronomical theory of glacial cycles (Milankovitch, 1941) postulates that growth and shrinkage of ice sheets is primarily controlled by changes in Earth's orbital parameters (eccentricity, obliquity and precession) through their effect on the amount 
https://doi.org/10.5194/esd-2021-2

Preprint. Discussion started: 1 March 2021

(c) Author(s) 2021. CC BY 4.0 License.

of solar radiation received at high latitudes of the Northern Hemisphere $(\mathrm{NH})$ during boreal summer. Different aspects of Milankovitch theory have been tested and confirmed with climate and Earth system models of different degree of complexity (e.g. Pollard, 1983; Berger et al., 1999; Ganopolski and Calov, 2011; Abe-Ouchi et al., 2013; Tabor and Poulsen, 2016; Willeit et al., 2019).

Different types of models have been used also to study long-term future evolution of the Earth system in response to anthropogenic influence, primarily, fossil fuel combustion. It has been shown that anthropogenic $\mathrm{CO}_{2}$ emissions can affect future climate variability even at very long timescales (Archer et al., 1997; Lenton and Britton, 2006; Ridgwell and Hargreaves, 2007) and it has been demonstrated that even the current cumulative anthropogenic emission of $500 \mathrm{GtC}$, when assuming no negative Carbon emission in the future, can postpone the onset of the next glaciation by at least $50 \mathrm{kyr}$ while an emission of 5000 GtC could completely change climate variability over the next 0.5 Myr (Archer and Ganopolski, 2005; Ganopolski et

45 al., 2016).

Aforementioned results not only demonstrate the long-term impact of the human activity but are also of practical importance for another type of anthropogenic activity: the permanent storage of the radioactive waste. Indeed, low- and intermediate-level nuclear wastes must be safely stored for at least 100 kyr years, while for high-level nuclear wastes and spent nuclear fuel, safety for 1 Myr should be envisaged. The safe disposal of such materials constitutes one of the urgent environmental and societal challenges that mankind faces in the 21st century. Disposal in deep geologically-stable rock formations is the only currently viable alternative to ensure long-term safety (IAEA Report 2007, Kim et al., 2011). The evaluation of geological disposal systems in response to future environmental changes, driven by a combination of natural (orbital variations) and anthropogenic (fossil fuel emissions) forcings (e.g. Lord et al., 2016) is, therefore, mandatory. However, these timescales are not "accessible" by complex Earth system models and result problematic even for most of the intermediate-complexity models. Moreover, while Earth orbital parameters are accurately known for the next millions of years (Laskar et al., 2004), large uncertainties associated with the total amount of fossil fuel combustion as well as the sensitivity of the Earth system to anthropogenic perturbations at multimillion years timescale, requires a computationally efficient modelling approach which permits the generation of quantitative probabilistic assessments. To this end we develop a reduced-complexity process-based model of the coupled climate - ice sheets - Carbon cycle evolution, whose only external forcings are insolation and cumulative anthropogenic $\mathrm{CO}_{2}$ emissions. By formulation, this model is similar to the so-called "conceptual models of glacial cycles" (e.g. Imbrie and Imbrie 1980; Paillard 1998; Tziperman 2006; Crucifix 2012). Some of these conceptual models simulate only global ice volume evolution while others also simulate variations in natural (i.e. past) $\mathrm{CO}_{2}$ concentration (e.g. Saltzman 1987; Saltzman and Verbitsky 1993; Paillard and Parrenin 2004). To account for the anthropogenic influence on the future glacial 65 cycles, Archer and Ganopolski (2005) used Paillard's conceptual model in conjunction with the results of future $\mathrm{CO}_{2}$ simulations performed with a box-model of marine Carbon cycle. Here, for the same purpose, we use a parameterization 
developed in Lord et al. (2016) based on simulations performed with the Earth system model of intermediate complexity cGENIE (Lenton et al., 2006).

70 The manuscript is organized as follows. In Sec. 2 we introduce the model and datasets. Results are presented in sections 3 and 4. Section 3 is devoted to the assessment of model performance. In Sec. 4 we present a probabilistic forecast for the future 1 Myr, under scenarios with and without anthropogenic influence. Finally, in Sec. 5 we summarize the results and present the conclusions.

\section{Model and datasets}

\section{$75 \quad 2.1 \quad$ Modelling approach}

To develop a probabilistic prediction of future climate we develop a process-based model for the coupled evolution of global ice volume, atmospheric $\mathrm{CO}_{2}$ concentration and global mean surface air temperature. For the past, the model's only external forcing is orbital forcing represented by the maximum summer insolation at $65^{\circ} \mathrm{N}$. For the future, we accounted additionally for the impact of the cumulative anthropogenic $\mathrm{CO}_{2}$ emissions on atmospheric $\mathrm{CO}_{2}$ concentration. The model consists of a

80 system of three coupled, non-linear differential equations, describing Earth system evolution at the timescales from thousands to millions of years. Using different sets of model parameters, we generate a probabilistic forecast of the evolution of the system over the next 1 million years under natural and anthropogenic $\mathrm{CO}_{2}$ release scenarios.

The model contains 12 parameters (see Table 1). Several of them were fixed using prior information, while others were treated

85 as "tunable" model parameters (see Sec. 2.5). For model calibration and testing, we use paleoclimate reconstructions for the last $800 \mathrm{kyr}$ (see below). This period was selected because it is dominated by the long glacial cycles which are expected to continue in the future, at least, for some time (see discussion below) in the absence of significant anthropogenic influence. Using empirical data and by varying model parameters, we generate a large subset of model realizations of which we select a subset with the highest correlations to paleodata. This subset has been then additionally reduced by requiring consistency with

90 the results of Ganopolski et al. (2016). This reduced subset of model realizations has been finally applied to modelling of the next million years for the natural (no anthropogenic $\mathrm{CO}_{2}$ emission) and several anthropogenic scenarios.

\subsection{Equation for global ice volume}

The first model equation describes the temporal evolution of global ice volume $v$ expressed in nondimensional units (with a value of 1 representative of Last Glacial Maximum (LGM) ice volume levels, according to empirical data). Since it is set that

95 at present $v=0$, this variable represent anomaly of global ice volume relative to the preindustrial state. As the principal natural forcing for global ice volume is summer $\mathrm{NH}$ insolation, it is natural to interpret it as the equation for only NH ice volume. To account for the contribution of the Southern Hemisphere (SH), we use the same approach as in Ganopolski and Calov (2011) 
and assume that the ice volume anomaly in the SH closely follows the $\mathrm{NH}$ anomaly and makes up a constant, relatively small faction of the global ice volume anomaly. This approach, obviously, is not applicable for a possible future Antarctic and Greenland melting under high $\mathrm{CO}_{2}$ concentrations. This is why we do not consider future sea level rise above the preindustrial level and it is required that $v \geq 0$ at any time (see below). The mass-conservation equation states that:

$\frac{d v}{d t}=($ Accumulation - Ablation $)$

“Accumulation” represents here the global ice accumulation (in mass per time units) and “Ablation” represents all mass losses from ice sheets including surface and basal melt, and icebergs calving. We assume that the total accumulation is proportional to the total ice sheet area (Ganopolski et al., 2010). In turn, ice sheet area is closely related to the ice volume. It is often assumed that $A=v^{\gamma}$, where $\gamma$ is about 0.8 . Here for simplicity we assume $\gamma=1$, and thus:

where $b$ is the proportionality constant.

On the other hand, the ablation is controlled by several processes of which the energy balance at the surface of the ice sheets

115 is the most important one. Total ablation depends on the size of the ice sheets (and in the NH, especially, on the position of their southern margin), summer insolation (orbital forcing) and $\mathrm{CO}_{2}$ atmospheric concentration $\left(\mathrm{CH}_{4}\right.$ and $\mathrm{N}_{2} \mathrm{O}$ also play a role but we assume their radiative forcing to be proportional to the radiative forcing of $\mathrm{CO}_{2}$ as in Willeit et al., 2019). The effect of $\mathrm{CO}_{2}$ on the mass balance of ice sheet is introduced via the logarithm of its concentration because radiative forcing of $\mathrm{CO}_{2}$ is proportional to the logarithm of concentration. As the metric for orbital forcing, as in Ganopolski (2021), we use the maximum summer insolation at $65^{\circ} \mathrm{N}$ computed using Laskar et al. (2004). Similar to Ganopolski et al. (2021), we introduced a term depending on dv/dt representing the "domino effect" during glacial termination. To ensure existence of at least one equilibrium solution (solution with $\mathrm{dv} / \mathrm{dt}=0$ ) for any combination of orbital and $\mathrm{CO}_{2}$ forcing a negative term proportional to the ice volume in power large than one is required (Calov and Ganopolski, 2005; Abe-Ouchi et al. 2013). While Ganopolski (2021) used term $v^{2}$, here we use the term $v^{3 / 2}$ since it gives a better model performance. Thus, the total ablation is represented as:

Ablation $=b_{01} v-b_{2} v^{3 / 2}-b_{3}(f-\bar{f})-b_{4} \log \left(\mathrm{CO}_{2}\right)+b_{5} \frac{d v}{d t} M_{v}-b_{06}$

where $\mathrm{b}_{01}, \mathrm{~b}_{2}, \ldots \mathrm{b}_{6}$ are constants, $\bar{f}$ is the average orbital forcing, and $M_{\mathrm{v}}$ is a memory term that reflects the history of the ice volume during the last $\tau \mathrm{yr}$, as long as $\mathrm{dv} / \mathrm{dt}$ is negative. At any time $t, M_{\mathrm{v}}(t)$ is defined as: 
$\delta=1$ if $\frac{d v}{d t}<0 ;$ and $\delta=0$ otherwise

Finally, setting $b_{1}=b-b_{01}$ and $b_{6}=b_{06} /\left(1+b_{5} M_{v}\right)$ the mass-balance Eq. (1) can be re-written as:

135

$\frac{d v}{d t}=\frac{b_{1} v+b_{2} v^{3 / 2}+b_{3}(f-\bar{f})+b_{4} \log \left(C O_{2}\right)}{1+b_{5} M_{v}}+b_{6}$

Where $b_{1} \ldots b_{6}$ are adjustable parameters.

\subsection{Equation for atmospheric $\mathrm{CO}_{2}$ concentration}

140 It is generally recognized that $\mathrm{CO}_{2}$ (together with other well-mixed greenhouse gases such as $\mathrm{CH}_{4}$ and $\mathrm{N}_{2} \mathrm{O}$ ) represents an important amplifier of glacial cycles and that the anthropogenic $\mathrm{CO}_{2}$ emission will affect the climate during long periods of time (Archer and Brovkin, 2008) and, in particular, the timing and magnitude of future glacial cycles (Archer and Ganopolski, 2005). Although the mechanisms of glacial-interglacial atmospheric $\mathrm{CO}_{2}$ variability are still not fully understood, significant progress in modelling the global Carbon cycle operation during glacial cycles has been achieved in recent times (Brovkin et

145 al., 2012; Menviel et al. 2012; Willeit et al. 2019). Since $\mathrm{CO}_{2}$ and ice volume are highly correlated (during the past $800 \mathrm{kyr}$ the coefficient of correlation between atmospheric $\mathrm{CO}_{2}$ concentration and ice volume is -0.71), it is not surprising that simple conceptual models of glacial cycles can describe the ice volume evolution without an explicit treatment of $\mathrm{CO}_{2}$ (e.g. Paillard 1998; Crucifix 2013; Ganopolski 2021). However, this close relationship between $\mathrm{CO}_{2}$ and global ice volume is not valid for the Anthropocene and, thus, the modelling of the future climate evolution requires an explicit treatment of atmospheric $\mathrm{CO}_{2}$ concentration which is the second equation of our model. The response of the global Carbon cycle to external perturbations involves a broad range of timescales: from very short (annual) to geological. For the purpose of this study we treat natural and anthropogenic anomalies of $\mathrm{CO}_{2}$ separately but consider them additive. Namely, we assume that on the relevant timescales $\left(10^{3}-10^{5} \mathrm{yrs}\right)$, the natural component of $\mathrm{CO}_{2}$ concentration is in equilibrium with external conditions and can be expressed through a linear combination of global temperature and global ice volume.

The most direct effect of temperature on $\mathrm{CO}_{2}$ is through changes in the $\mathrm{CO}_{2}$ solubility in ocean water (Zeebe and WolfGladrow, 2001). Temperature, directly and through sea ice, also affects ocean circulation (Watson et al., 2015), ventilation rate of the deep water (Kobayashi et al., 2015), changes in relative volume of different water masses (Brovkin et al., 2007) and metabolic rates of living organisms (Eppley, 1972; Laws et al., 2000). 
The direct effect of ice volume on $\mathrm{CO}_{2}$ changes is less straightforward (please note that the strong effect of ice sheets on atmospheric temperature is already accounted for in the temperature term). An increase in ice volume leads to a decrease of the ocean volume and, as a consequence, increased ocean salinity. As $\mathrm{CO}_{2}$ solubility in the ocean decreases with salinity this would provoke to an increase of atmospheric $\mathrm{CO}_{2}$ concentration, counteracting the temperature effect (Zeebe and WolfGladrow, 2001). Higher global ice volume would also mean a smaller area of the globe is covered by forests and, therefore, a diminished carbon storage in the terrestrial reservoir, driving an increase in atmospheric $\mathrm{CO}_{2}$ (Prentice et al., 2011). Increased glacial supply of iron-rich dust may help suppress the iron limitation in some areas (in particular in the south Atlantic Ocean) leading to increased biological productivity and thus lower atmospheric $\mathrm{CO}_{2}$ levels (Martin, 1990; Watson et al., 2000).

In addition, based on results of Ganopolski and Brovkin (2017) we parameterized $\mathrm{CO}_{2}$ "overshoots" during glacial terminations by an additional term proportional to $\mathrm{d} v / \mathrm{d} t$. Note that this additional term is only applied when $\mathrm{d} v / \mathrm{d} t<0$. The justification for such parameterization is the results seen in many models (Gottschalk et al., 2019) that a shutdown of the Atlantic Meridional Overturning Circulation (AMOC) causes an atmospheric $\mathrm{CO}_{2}$ rise of about 10-20 ppm. A shutdown of the AMOC is caused by a large meltwater flux which is, in turn, controlled by changes in ice volume (i.e. $\mathrm{d} v / \mathrm{d} t$ ).

To describe the anthropogenic component of $\mathrm{CO}_{2}$, we assume that anthropogenic $\mathrm{CO}_{2}$ emission is a relatively short (order of $10^{2} \mathrm{yrs}$ ) pulse followed by zero emissions. In this case, the temporal dynamics of the anthropogenic component of $\mathrm{CO}_{2}$ anomaly depends only on the cumulative Carbon emission. To describe the long anthropogenic tail of $\mathrm{CO}_{2}$ (AnthCO2 term in the Eq. (7) below) we use the analytical parameterization defined in Lord et al. (2016) based on the results of experiments with the 180 Earth system model of intermediate complexity cGENIE (Lenton et al., 2006). In addition, we assume that natural and anthropogenic $\mathrm{CO}_{2}$ anomalies can be simply summed up and that at the preindustrial time the global Carbon cycle was in equilibrium. This is, obviously, a very strong assumption since even a rather small imbalance in the global Carbon cycle which is impossible to detect at the millennial timescales can result in a very large "drift" of the Earth system from its preindustrial state at the million years timescale. However, due to the absence of any practical alternative, we proceeded with this assumption.

After these considerations, the equation that governs the $\mathrm{CO}_{2}$ evolution has the following shape:

$C O_{2}=c_{1} d T+c_{2} v+c_{3} \min \left(\frac{d v}{d t}, 0\right)+c_{4}+A n t h_{C O_{2}}$

Where $c_{1} \ldots c_{4}$ are adjustable model parameters. The first three terms on the right-hand-side of equation (7) represent the already discussed effects of global temperature, ice volume and AMOC weakening or shutdown. The fourth term ( $\left.\mathrm{C}_{4}\right)$ is simply a constant and the last term represents external forcing due to anthropogenic processes (and we are, thus, assuming that 
anthropogenic emissions occur on top of the natural Carbon cycle as a linear addition). Please, refer to Sec. 4.1 for a detailed explanation on the assumptions and shape of the function Anth $_{\mathrm{CO} 2}(\mathrm{t})$.

\subsection{Equation for global mean surface temperature}

The last equation in our model describes global mean surface air temperature anomaly ( $\Delta$; relative to preindustrial values) as a linear function of global ice volume and logarithm of $\mathrm{CO}_{2}$ concentration:

$200 \Delta T=d_{1} v+d_{2} \log \left(\frac{\mathrm{CO}_{2}}{278}\right)$,

where $d_{1}$ and $d_{2}$ are adjustable model parameters.

\subsection{Model constraints, bounds and parameter selection strategy}

The model of past and future glacial cycles is represented by the system of three equations (6), (7), (8) which contains three

205 variables $v, \mathrm{CO}_{2}$ and $\Delta T$, orbital forcing $f(\mathrm{t})$, anthropogenic $\mathrm{CO}_{2}$ anomaly Anth $\mathrm{CO}_{2}(\mathrm{t})$ and twelve parameters $\left(b_{\mathrm{i}} \mathrm{i}=1: 6 ; c_{\mathrm{j}} \mathrm{j}=1: 4\right.$, $\left.d_{\mathrm{k}} \mathrm{k}=1: 2\right)$. The orbital forcing $f(\mathrm{t})$ depends only on astronomical parameters (eccentricity, precession and obliquity) which are accurately known for the entire period of interest (Laskar et al., 2004). The function Anth $\mathrm{CO}_{2}(\mathrm{t})$ is assumed to be null until $\mathrm{t}=$ $0 \mathrm{kyr}$, afterwards the function depends only on time and cumulative $\mathrm{CO}_{2}$ emission as detailed in Sec. 4.1.

210 Model parameters are selected to yield solutions that are in a good (see discussion below) agreement with the paleoclimatic information over the last 800kyr (see Sec. 2.6 for details on the paleoclimate reconstructions used). To determine some of model parameters and thus reduce the number of "free parameters" we use three conditions based on paleoclimatic data and current estimations of equilibrium climatic sensitivity.

215 The first constraint is related to preindustrial conditions. We require that if $v=0$ and $\Delta \mathrm{T}=0$, then $\mathrm{CO}_{2}=278 \mathrm{ppm}$. This condition fixes the value for $c_{4}$ at 278 .

As the confidence on empirical data for glacial conditions is higher at LGM than at any other glacial episode, the reproduction of LGM conditions is the only constraint that we will require from the model. At LGM, empirical ice volume in non220 dimensional units was $1, \mathrm{CO}_{2}$ concentration $194 \mathrm{ppm}$ and global cooling around $5^{\circ} \mathrm{C}$ (Schneider et al., 2006; Annan et al., 2013; Tierney et al., 2020). We then require from the model that:

if $v=1 \& \mathrm{CO}_{2}=194 \mathrm{ppm} \rightarrow \Delta T=-5^{\circ} \mathrm{C}$ 
225 The last imposed criteria is related to the current estimates for the equilibrium climatic sensitivity, i.e. global temperature response to a doubling in atmospheric $\mathrm{CO}_{2}$ concentration from preindustrial levels. We select a climate sensitivity equal to 3.9 C, which coincides with the multimodel mean in the Coupled Model Intercomparison Project 6 (CMIP6; Zelinka et al., 2020):

if $\mathrm{CO}_{2}=2 x 278 p p m \& v=0 \rightarrow \Delta T=3.9^{\circ} \mathrm{C}$.

Equations (10) and (11) determine the values for the coefficients $d_{1}$ and $d_{2}$ at -3 and 5.56, respectively.

With these additional constraints, the initial set of twelve independent parameters shrinks to a total of nine: $P=\left\{b_{i} ; c_{j}\right\} i=$ $1: 6, j=1: 3$.

235

Furthermore, to prevent the selection of parameters that will lead to unrealistic values for the selected variables we also apply two limitations.

The first limitation is applied to the simulated ice volume $v$. First, we assume that for the recent interstadials and any future time, $v$ cannot be negative. Second, it is known that glacial cycles prior to the mid-Brünhes Transition (MBT) about 400 kyr ago differ in some respects from those after MBT. In particular, pre-MBT interglacials were characterised by lower $\mathrm{CO}_{2}$ and higher benthic $\mathrm{d}^{18} \mathrm{O}$ values than the post-MBT episodes. The later implies a large interglacial, probably due to remaining continental ice sheets in the NH. The mechanisms accounting for these differences are still not understood (Tzedakis et al., 2009; Berger et al., 2016) but they are unlikely related to differences in orbital forcing before and after MBT. This is why it is not expected that a simple model forced by orbital variations alone can simulate such behaviour. This is why we prescribe that before the MBT the minimum ice volume must be 0.05 in normalized units:

$$
\begin{aligned}
& v(t)=\max (v(t), 0.05) \text { if } \mathrm{t}<-400 \mathrm{kyr} \\
& v(t)=\max (v(t), 0) \text { if } \mathrm{t} \geq-400 \mathrm{kyr}
\end{aligned}
$$

The second limitation, based on empirical data, prevents $\mathrm{CO}_{2}$ to drop to levels significantly lower than the minimum atmospheric $\mathrm{CO}_{2}$ concentration registered in the last $800 \mathrm{kyr}$ by paleorecords (172 ppm) at any given moment in time:

$\mathrm{CO}_{2}(t)=\max \left(\mathrm{CO}_{2}(t), 150\right)$

In addition, we applied a constraint which is not from the past but from the future. Several modeling studies (Berger and Loutre, 2002; Cochelin et al., 2006; Ganopolski et al., 2016) indicate that the conditions for the new glacial inception will not 
be met in the near future even in the absence of anthropogenic influence on climate. To assure that our model satisfies this requirement, we require for all valid model versions the average global ice volume not to exceed 0.025 (in normalized units) in the time period between 0 and $20 \mathrm{kyr}$ :

$\frac{\sum_{t=0}^{20 k y r} v(\mathrm{t})}{21}<0.025$

Finally, we approach the task of the selection of set of parameters $\mathrm{P}$ as a non-linear optimisation problem with equality and inequality constraints. We wish to find $\mathrm{P}$ to maximize the optimization target function $\mathrm{C}_{\mathrm{v}}$ :

$C_{v}\left(P, t_{i}, t_{f}\right)=\operatorname{corr}\left(v_{\text {model }(P)}\left(t_{i}, t_{f}\right), v_{\text {Paleo }}\left(t_{i}, t_{f}\right)\right)$

where: $v_{\text {model }(P)}\left(t_{i}, t_{f}\right)$ denotes the modelled ice volume time-series in the period $\left[t_{i}, t_{f}\right]$ (i.e. solution obtained for $\mathrm{v}$ when using the parameter set $\mathrm{P}$ in the system (6-8)); $v_{\text {Paleo }}\left(t_{i}, t_{f}\right)$ denotes the paleo ice volume time-series in the period $\left[t_{i}, t_{f}\right]$; $\operatorname{corr}(x, y)$ denotes the linear Person correlation between $\mathrm{x}$ and $\mathrm{y}$. The time interval for the optimisation is set to $\left[t_{i}, t_{f}\right]=$ [-800 kyr, $0 \mathrm{kyr}]$. See Appendix A for a discussion of the dependence of model performance on the choice of this time interval. To select parameters that will optimise correlation at the same time as providing magnitudes in accordance to empirical estimations, an equality constraint is enforced: the maximum ice volume must be equal to 1 within a tolerance of 0.15 (in nondimensional units). Finally, the inequality constraint is given by Eq. (14).

The time-step for the calculation of the time-series is $1 \mathrm{kyr}$. We use the interior-point optimisation algorithm under the Matlab environment. Approximately 1000 optimisation routines were performed, each starting from a different combination of the set of nine adjustable parameters (optimisation seeds).

Finally, the ensemble of valid solutions, Valid, is defined as the set:

Valid $=\left\{P / C_{v}(P,-800 \mathrm{kyr}, 0 \mathrm{kyr}) \geq 0.7\right\}$

285 The correlation level of 0.7, although arbitrary, guarantees a good fit to the paleo climatic ice volume record. For the selection of solutions, no conditions are imposed on the goodness of fit between modelled and paleo $\mathrm{CO}_{2}$ or temperature. For each $\mathrm{P}$, we calculate $v, \mathrm{CO}_{2}$ and $\Delta \mathrm{T}$ obtained using $\mathrm{P}$ in the system of equations (6), (7), (8) and denote them: $v_{\text {model }(P)}, C O_{2 \operatorname{model}(P)}, d T_{\text {model }(P)}$. This ensemble provides the basis to generate the probabilistic forecast in the remainder of the paper. 


\section{$290 \quad 2.6 \quad$ Empirical datasets}

Paleo reconstructions covering the period [-800 kyr, $0 \mathrm{kyr}$ ] are used as part of the learning and/or validation sets for the model. Reconstructed global ice volume is derived from sea level stack (Spratt and Lisiecki, 2016). Past $\mathrm{CO}_{2}$ atmospheric concentration levels are derived from ice cores records (Lüthi et al., 2008). For global mean surface temperature anomalies (with respect to preindustrial conditions) we use two reconstructions: 1. Friedrich et al. (2016), which covers the period [-784 kyr, $-10 \mathrm{kyr}$ ] and 2. Snyder (2016), covering [-800 kyr, -1 kyr]. All datasets are transformed into time-series with a 1 kyr timestep.

\section{Model performance}

In this section we analyse the model's performance considering the parameter combinations P belonging to the Valid ensemble. First, we evaluate the model performance by comparison of model simulations to paleoclimate reconstructions. Second, we analyse the critical insolation $-\mathrm{CO}_{2}$ relationship during glacial inception episodes for the different model realizations derived from Valid and compare them with Ganopolski et al. (2016).

For each $\mathrm{P}$ in Valid (353 in total), we calculate $v_{\operatorname{model}(P)}, \mathrm{CO}_{2 \operatorname{model}(P)}, d T_{\text {model }(P)}$.

\subsection{Comparison with paleoclimate reconstructions}

305 Figure 1 displays the ensemble probabilistic distribution of solutions in Valid for $v, \mathrm{CO}_{2}$ and $\Delta \mathrm{T}$ as well as the corresponding paleoclimatic analogues for the period [-800 kyr, $0 \mathrm{kyr}$ ]. The ranges of the different model parameters across the Valid set are displayed in Table 1.

By definition, all the solutions derived from the Valid ensemble closely follow the paleo ice volume curve (Fig. 1a), with the 310 ensemble-mean correlation between modelled and paleo ice volume in [-800 kyr, $0 \mathrm{kyr}$ ] equal to 0.76 . While most of the solutions derived from Valid succeed in capturing the timing and magnitude of the major glaciations, there is a tendency for them to overestimate the ice volume in MIS 18 and MIS 14 (-560 kyr and -520 kyr, respectively). . As model parameters were chosen to maximise ice volume correlation only, it is expected that the performance in terms of $\mathrm{CO}_{2}$ and global temperature is inferior than for global ice volume. The ensemble-mean correlation between modelled and paleo $\mathrm{CO}_{2}$ is 0.5 and some solutions

315 display an amplitude range significantly larger than the observed one, reaching the imposed lower limit of 150 ppm (Fig. 1b). For global mean surface temperature (Fig. 1c), the ensemble-mean correlation between modelled and paleo record is 0.56 and the solutions amplitude range within the paleo estimation limits. 
Table 1: Parameter ranges across solutions in the Valid and Accepted sets as well as for the Best Solution.

\begin{tabular}{|c|c|c|c|}
\hline model Parameter & Valid set & Accepted set & Best Solution \\
\hline $\mathbf{b}_{\mathbf{1}}$ & $0.075-0.27$ & $0.12-0.26$ & -0.29 \\
\hline $\mathbf{b}_{2}$ & $-0.49--0.15$ & $-0.33--0.15$ & $-8 \times 10^{-4}$ \\
\hline $\mathbf{b}_{3}$ & $-9 \times 10^{-4}--3 \times 10^{-4}$ & $-9 \times 10^{-4}--5 \times 10^{-4}$ & -0.095 \\
\hline $\mathbf{b}_{4}$ & $-0.62--0.02$ & $-0.12--0.02$ & -0.18 \\
\hline $\mathbf{b}_{\mathbf{5}}$ & $-1--0.04$ & $-0.76--0.13$ & 0.53 \\
\hline $\mathbf{b}_{6}$ & $0.1-3.49$ & $0.1-0.66$ & 17.28 \\
\hline $\mathbf{C}_{1}$ & $10.6-18.84$ & $12.37-18.84$ & -31.95 \\
\hline $\mathbf{C}_{2}$ & $-35.1--20.0$ & $-35.1--22.87$ & -120.0 \\
\hline $\mathbf{C}_{3}$ & $-120.1--119.9$ & $-120.03--119.9$ & 278 \\
\hline $\mathbf{C}_{4}$ & 278 & 278 & -3 \\
\hline $\mathbf{d}_{1}$ & -3 & -3 & 5.56 \\
\hline $\mathbf{d}_{2}$ & 5.56 & 5.56 & \\
\hline
\end{tabular}

While the model demonstrates a good performance when tested against the same data that was used for its training, its ability to produce predictions (situation in which previously unseen data is used as model input) can only be evaluated by the use of independent training and validation samples. A robust estimation of the model's predictive skill, using disjoint training and validation sets, can be found in Appendix A. In general, we conclude that the model has a satisfactory ability also when used in predictive mode and, thus, we confidently venture to utilize it as a tool for the forecast of the next 1 Myr climatic evolution.

Table 2: Summary of Valid and Accepted ensembles characteristics.

\begin{tabular}{|c|c|c|}
\hline & Valid & Accepted \\
\hline $\begin{array}{c}\text { Correlation between modelled and } \\
\text { paleo ice volume }\end{array}$ & $\geq 0.7$ & $\geq 0.7$ \\
\hline $\mathbf{K}\left(\mathbf{W ~ m}^{-2}\right)$ & Unrestricted & $\geq-150$ \\
\hline Number of elements & 353 & 29 \\
\hline
\end{tabular}


https://doi.org/10.5194/esd-2021-2

Preprint. Discussion started: 1 March 2021

(c) Author(s) 2021. CC BY 4.0 License.

(a)

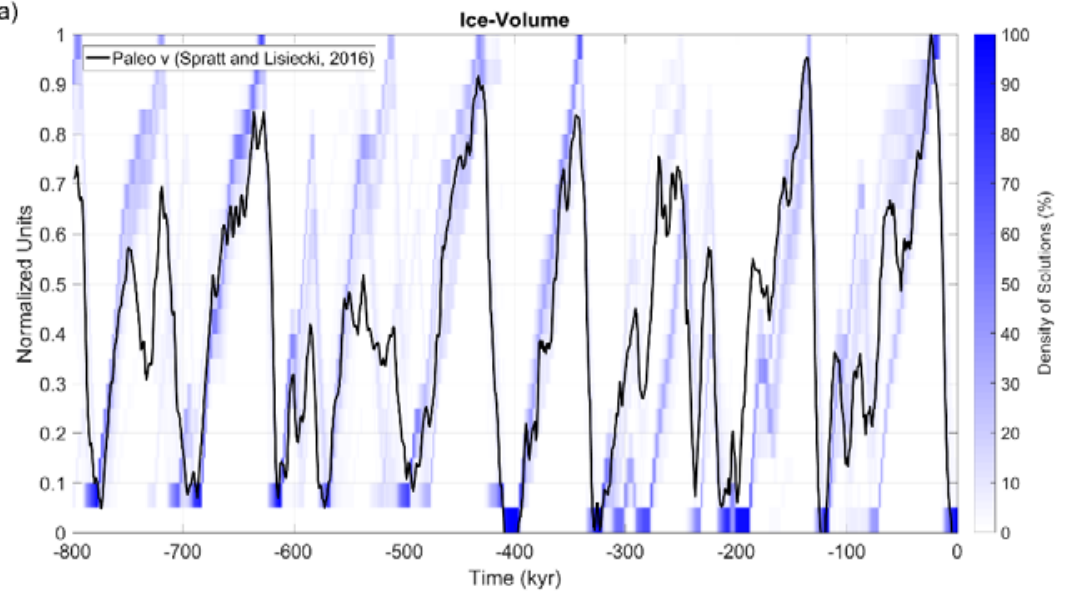

(b)

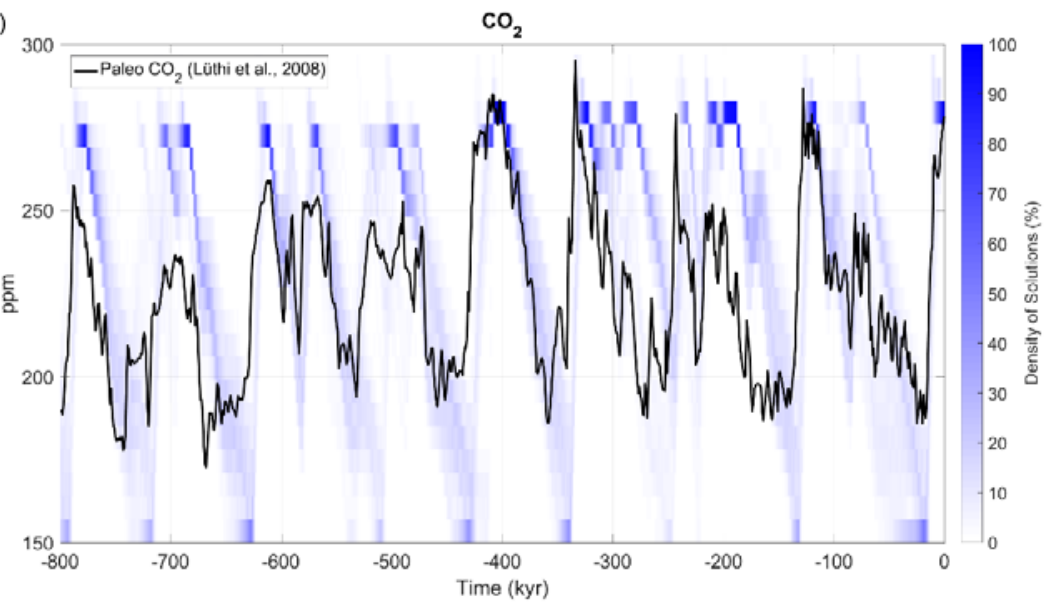

(c)

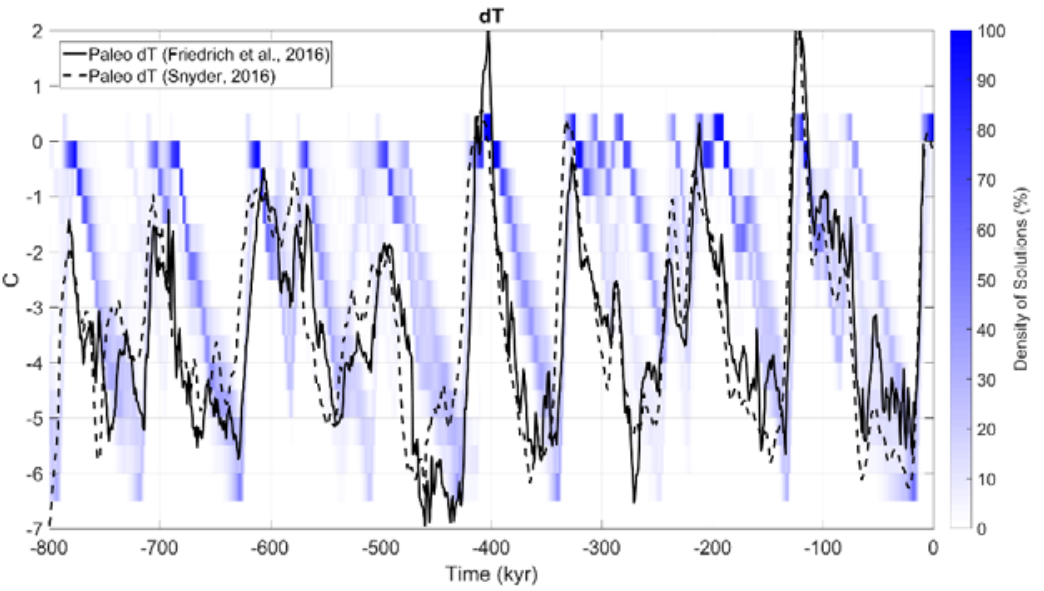

Figure 1: Probabilistic distribution of Valid solutions and paleoclimatic records in the period [-800 kyr, 0 kyr]: a. Global landmass ice volume (normalized to unity); reconstruction (black line) from Spratt and Lisiecki (2016). b. Atmospheric $\mathrm{CO}_{2}$ concentration 
(ppm); paleorecord from Lüthi et al. (2016). c. Global mean surface temperature anomaly (C); paleorecords from Friedrich et al. (2016) (solid black) and Snyder (2016) (dashed). For model simulations blue shaded area represents probability of the solution per unit of phase space: time unit is set to $1 \mathrm{kyr}$, ice volume to $0.05, \mathrm{CO}_{2}$ to $7 \mathrm{ppm}$ and temperature to $0.5 \mathrm{C}$.

\subsection{Glacial inception: Critical insolation $-\mathrm{CO}_{2}$ relationship}

Using a series of CLIMBER-2 model realizations consistent with paleo climatic constraints, Ganopolski et al. (2016) found that the critical threshold for summer insolation at $65^{\circ} \mathrm{N}$ to trigger glacial inception follows a functional relationship with $\mathrm{CO}_{2}$ atmospheric concentration. Given that the radiative forcing of $\mathrm{CO}_{2}$ is proportional to the logarithm of $\mathrm{CO}_{2}$ concentration and that in the CLIMBER-2 the temperature response to $\mathrm{CO}_{2}$ and orbital forcing is approximately linear within the considered range of $\mathrm{CO}_{2}$ concentrations, the critical summer insolation at $65^{\circ} \mathrm{N}$ can be described as:

$f_{\text {critical }}=\operatorname{Klog}\left(\mathrm{CO}_{2} / 280\right)+R$

where $\mathrm{K}=-77 \mathrm{~W} \mathrm{~m}^{-2}$ and $\mathrm{R}=466 \mathrm{~W} \mathrm{~m}^{-2}$. Following their approach, we calculate the corresponding coefficient $\mathrm{K}$ for each of the ensemble members in the Valid set (Fig. 2). Our results indicate that with the model derived in this study the possible values of the coefficient $\mathrm{K}$ range between -1279 and $-31 \mathrm{~W} \mathrm{~m}^{-2}$, with a median of $-393 \mathrm{~W} \mathrm{~m}^{-2}$. This highlights that, even though all the solutions derived from the Valid set have a high level of agreement with the paleoclimatic records along last $800 \mathrm{kyr}$, the relationship between $\mathrm{f}_{\text {critial }}$ and $\log \left(\mathrm{CO}_{2}\right)$ is not well constrained by paleoclimate data, i.e model realisations with complitely different values of $\mathrm{K}$ can produce similarly good agreement with the paleoclimate reconstructions. However, for the future simulations different $\mathrm{K}$ values lead to very different impact of anthropogenic $\mathrm{CO}_{2}$ emissions on the Earth system evolution (see Fig. 3 and the discussion below). This is why we propose carrying forward only those solutions in Valid which are consistent with Ganopolski et al. (2016), i.e. satisfy the condition $\mathrm{K} \geq-150 \mathrm{~W} \mathrm{~m}^{-2}$. With this choice we tried to account for the fact that this value can be strongly model-dependent. This sub-ensemble, which we call Accepted, consists of 29 elements. A summary of the characteristics of the Valid and Accepted ensembles can be found in Table 2. The probabilistic distribution of solutions for $\mathrm{v}, \mathrm{CO}_{2}$ and $\Delta \mathrm{T}$ derived from Accepted is displayed in Fig. 4 and the ranges of the different model parameters across Accepted can be found in Table 1.

In addition, we define the Best Solution PBest as:

$$
P_{\text {Best }}=\operatorname{Argmax}\left(C_{v}(P,-800 \text { kyr }, 0 k y r), P \in \text { Accepted }\right)
$$

$370 P_{\text {Best }}$ values can be find in Table 1. The time-series $v_{\text {model }\left(P_{B e s t}\right)}, C_{2 \operatorname{model}\left(P_{\text {Best }}\right)}, \Delta T_{\text {model }\left(P_{\text {Best }}\right)}$ are shown in Fig. 4 . The model Best Solution is rather successful in reproducing the observed climatic variability in the three considered variables for 
the whole [-800 kyr, $0 \mathrm{kyr}$ ] period. The model skill in reproducing both the temporal variability and amplitudes of the timeseries fluctuations is remarkable. In particular, the performance for ice volume is excellent with a correlation between model and paleodata of 0.86 (Fig. 4a). The model is able to correctly capture the timing of all the glaciations, being the LGM the highest volume event. The ice volume model and paleorecord discrepancy is largest for MIS 18 ([-750 kyr, -710 kyr]). The frequency spectra of $v_{\text {model }\left(P_{\text {Best }}\right)}$ and the empirical estimation are also in good agreement (Fig. 5): there is a clear dominant peak at 100 kyr, with additional power at 41 and 23 kyr. For atmospheric $\mathrm{CO}_{2}$ concentration, the correlation between modelled and recorded series is 0.62 (Fig. 4b). While the model succeeds in reproducing glacial-interglacial variability, it overestimates its magnitude: around $130 \mathrm{ppm}$ instead of $80 \mathrm{ppm}$. It is, in particular, evident that during interglacials the $\mathrm{CO}_{2}$ restores to its equilibrium value of $278 \mathrm{ppm}$, which according to the paleorecords is not accurate before the MBT. Finally, the correlation between modelled and paleo global mean surface temperature anomalies is 0.54 (Fig. 4c). The model slightly underestimates the variability of this variable, ranging between $0^{\circ} \mathrm{C}$ and $-5^{\circ} \mathrm{C}$, while the observational information suggests a larger range between $2^{\circ} \mathrm{C}$ and $-7^{\circ} \mathrm{C}$. The high positive temperature anomalies during some previous interglacials, however, are questionable.

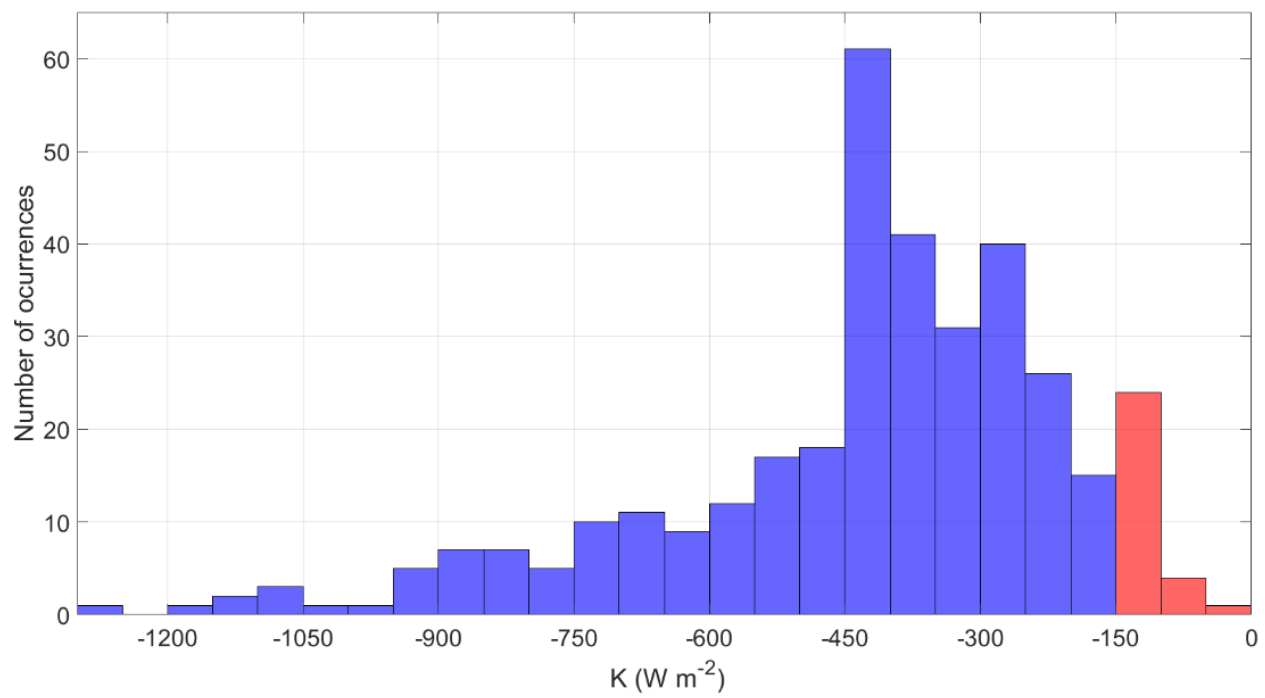

Figure 2: Histogram for K (see Eq. (17)) across the different members of the Valid ensemble of solutions. Red bars correspond to the Accepted solutions. 


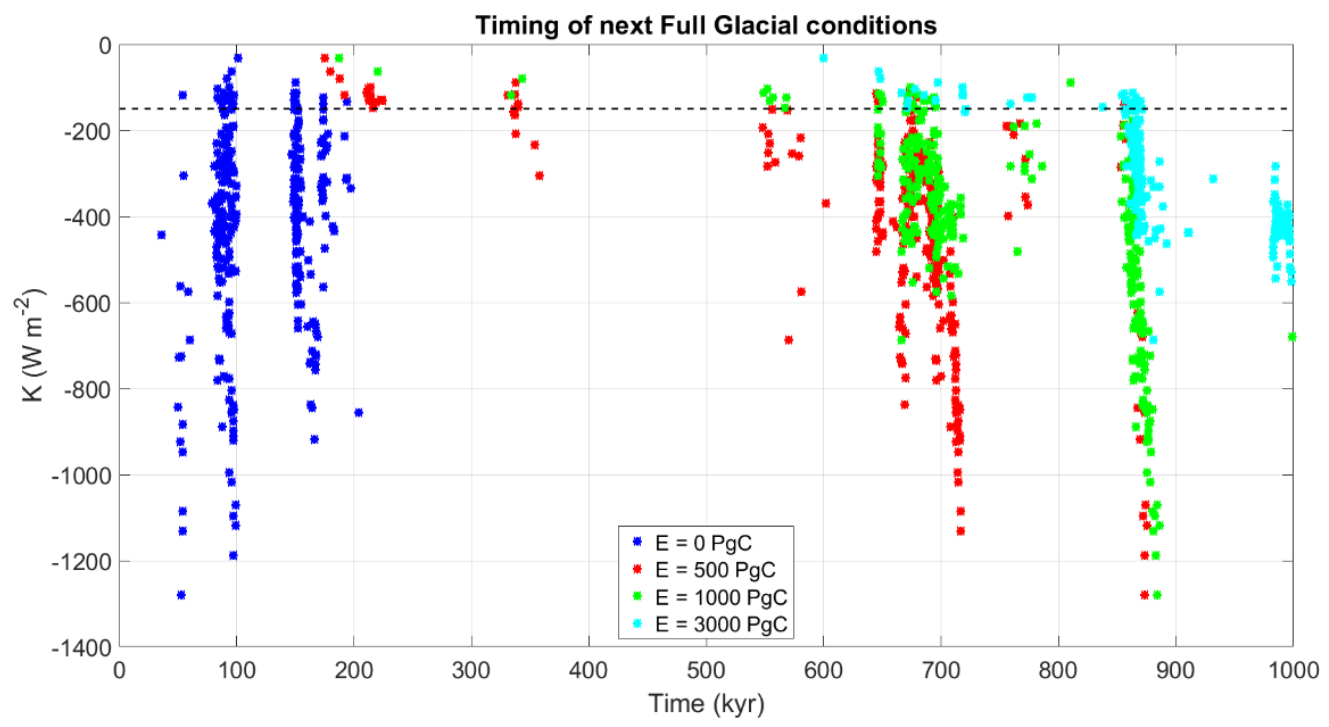

Figure 3: Dependence of timing of the next full glacial conditions $(\mathrm{v}=\mathbf{0 . 5})$ on parameter $\mathrm{K}$, for all solutions in Valid and under the different emission scenarios considered. The black dashed line indicates the value of $K=-150 \mathrm{~W} \mathrm{~m}^{-2}$, which is the limit for the solutions in the Accepted set.

\section{Next 1 Myr}

In this section we produce probabilistic forecasts of the evolution of the Earth system in the next 1 Myr, considering natural and anthropogenic emissions scenarios. For the probabilistic forecast we evaluate the future evolution of the solutions derived from the Accepted ensemble.

\subsection{Description of scenarios}

Future scenarios are generated considering different temporal evolution for the excess atmospheric $\mathrm{CO}_{2}$ concentration, which we assume depends only on the cumulative amount of fossil-fuel combustion, Anth $\mathrm{CO}_{2}(\mathrm{t}$ ) (see Eq. (7)). For the natural scenario,

400 Anth CO2 $_{(t)}$ is assumed to be zero at all times and, as a consequence, the climate system follows its natural evolution forced only by changes in orbital forcing. 
https://doi.org/10.5194/esd-2021-2

Preprint. Discussion started: 1 March 2021

(c) Author(s) 2021. CC BY 4.0 License.

(a)

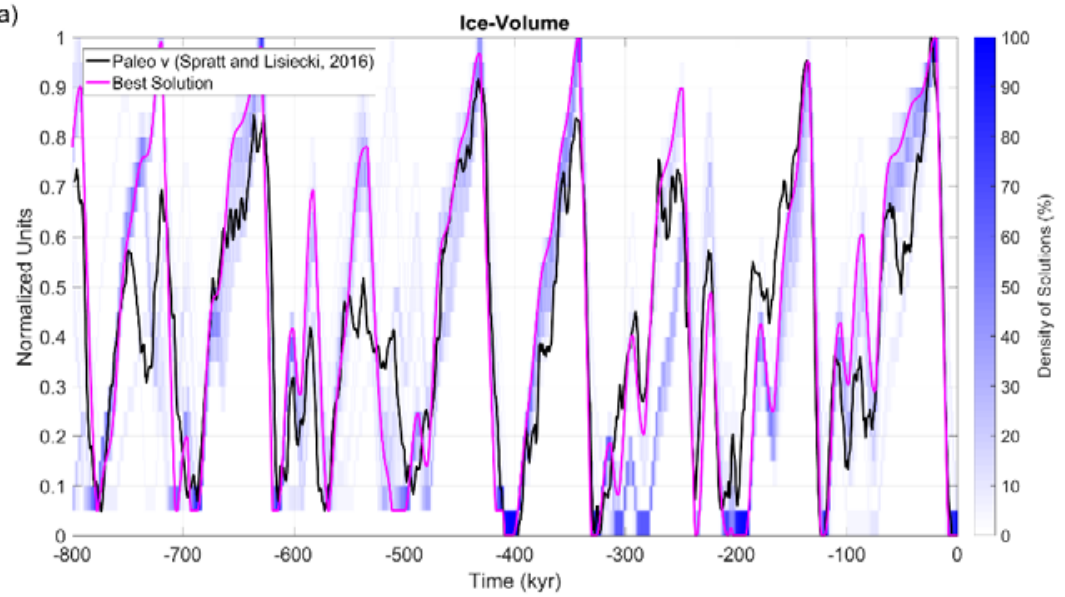

(b)

$\mathrm{CO}_{2}$

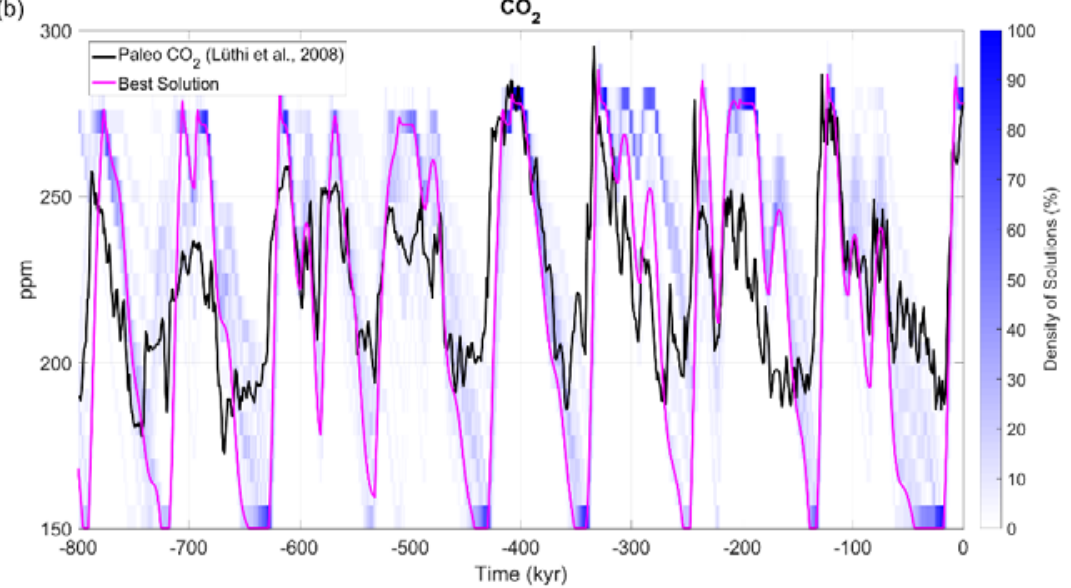

(c)

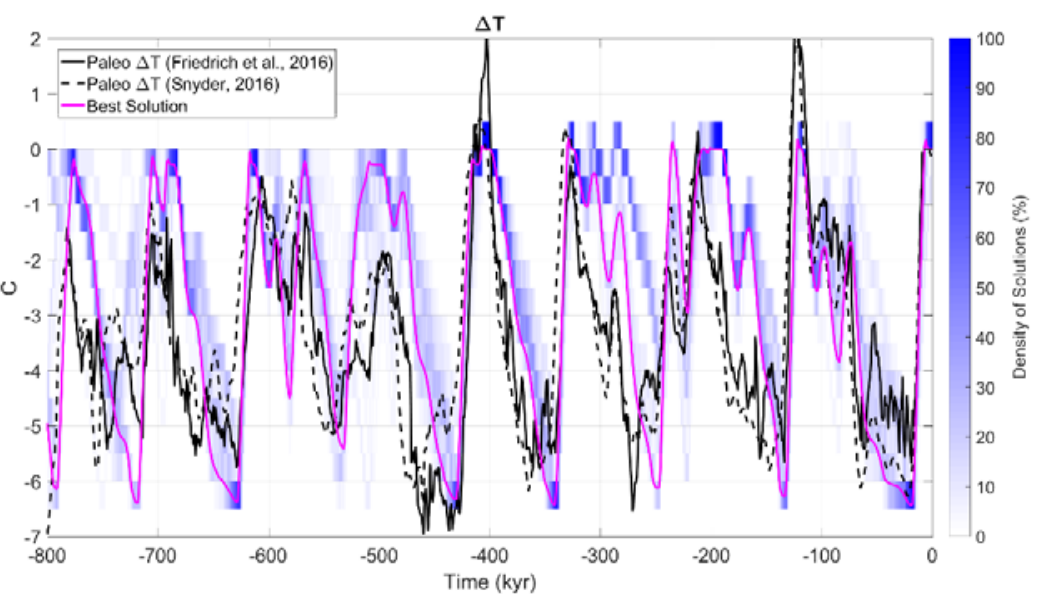

405

Figure 4: Same as Fig.1 but for solutions in the Accepted ensemble. In addition, magenta lines show the evolution of the Best Solution. 


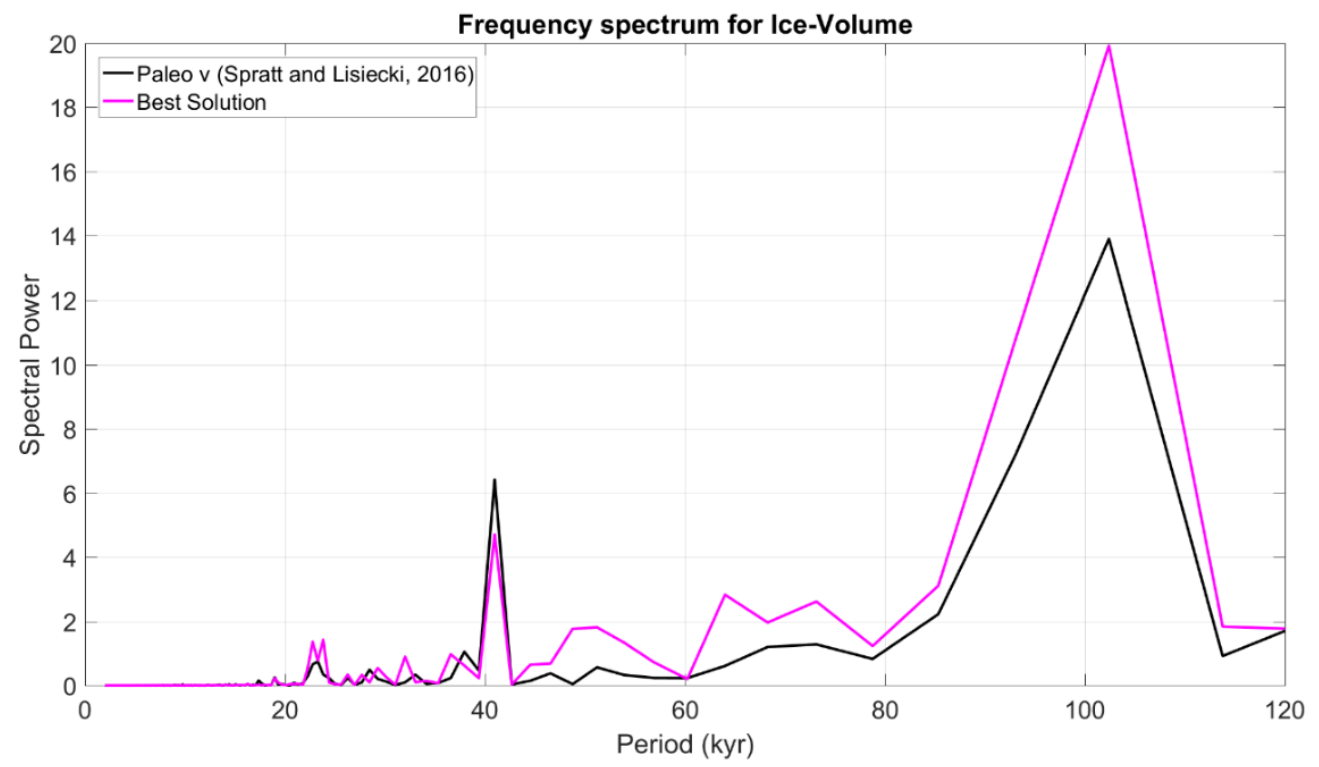

Figure 5: Frequency spectrum for simulated (Best Solution, magneta) and reconstructed ice volume (Spratt and Lisiecki, 2016; black).

For the fossil-fuel emission scenarios, we consider instantaneous releases of $\mathrm{CO}_{2}$ at $\mathrm{t}=0$, of different magnitudes. If the duration of the emission pulse release is rather short (centuries) and is followed by zero $\mathrm{CO}_{2}$ emission, the future long-term evolution of $\mathrm{CO}_{2}$ depends primarily on the cumulative emission magnitude while the rate of release is only of secondary relevance (Eby et al., 2009). For the period 1750-2017, estimations place the fossil-fuel cumulative emissions in Carbon equivalent at 660 +/- 95 PgC (Le Quéré et al., 2018). Projections for future cumulative emissions range between 700 PgC and 3000 PgC, being the former an estimate of fossil-fuel reserves exploitable with today's technical and economic constraints and the latter an estimation considering reserves that might become exploitable in the future (McGlade and Ekins, 2015). Taking into account the already achieved and future cumulative emissions estimations, we generate three different scenarios: low, intermediate and high emissions, corresponding to instantaneous pulse releases of magnitude 500 PgC, 1000 $\mathrm{PgC}$ or $3000 \mathrm{PgC}$, respectively. In each scenario, after the pulse release, Anth $\mathrm{CO}_{\mathrm{C}}(\mathrm{t})$ follows a multi-exponential decay function as proposed by Lord et al. (2016):

$A{ }^{2} h_{\mathrm{CO}_{2}}(t)=0.469 * E \sum_{i=1}^{5} A_{i} e^{-t / \tau_{i}}$

$A_{i}(E)=\alpha_{i}+\beta_{i 1} E+\beta_{i 2} E^{2}+\beta_{i 3} E^{3}$

$\tau_{i}(E)=\gamma_{i}+\delta_{i 1} E+\delta_{i 2} E^{2}+5 \delta_{i 3} E^{3}$ 
where $\mathrm{E}(\mathrm{PgC})$ represents the cumulative fossil-fuel emission magnitude, the constant 0.469 transforms PgC to $\mathrm{ppm}$ of $\mathrm{CO}_{2}$ and Anth $\mathrm{CO}_{2}(\mathrm{t})$ is expressed in units of ppm. Parameter values $\left(\alpha_{i}, \beta_{i j}, \gamma_{i}, \delta_{i j} \mathrm{i}=1, \ldots, 5 ; \mathrm{j}=1, \ldots, 3\right)$ are derived in Lord et al. (2016) in order to produce a good fit to a series of 1 Myr pulse-type of experiments performed with the $c$ GENIE EMIC (Lenton et al., 2006). Lord et al. (2016) consider total anthropogenic $\mathrm{CO}_{2}$ emissions ranging between 0 PgC to 20.000 PgC, where the latter value is justified assuming future techno-economic advances could make additional non-conventional resources such as methane clathrates available for extraction. The function Anth $\mathrm{CO}_{\mathrm{C}}(\mathrm{t})$ from present until 1 million years into the future, under the low, intermediate and high emissions scenarios is shown in Fig. 6. 100 kyr after the (low, intermediate or high) emissions pulse release $\sim 5 \%$ of the initial $\mathrm{CO}_{2}$ anomaly is still present in the atmosphere. For the low emissions scenario, only $500 \mathrm{kyr}$ after the pulse emission the do the remaining anthropogenic $\mathrm{CO}_{2}$ concentration anomalies drop below $1 \%$ of the original perturbation, marking the return of the system to its natural evolution. For the medium and high emission scenarios, the return to natural conditions takes even longer.

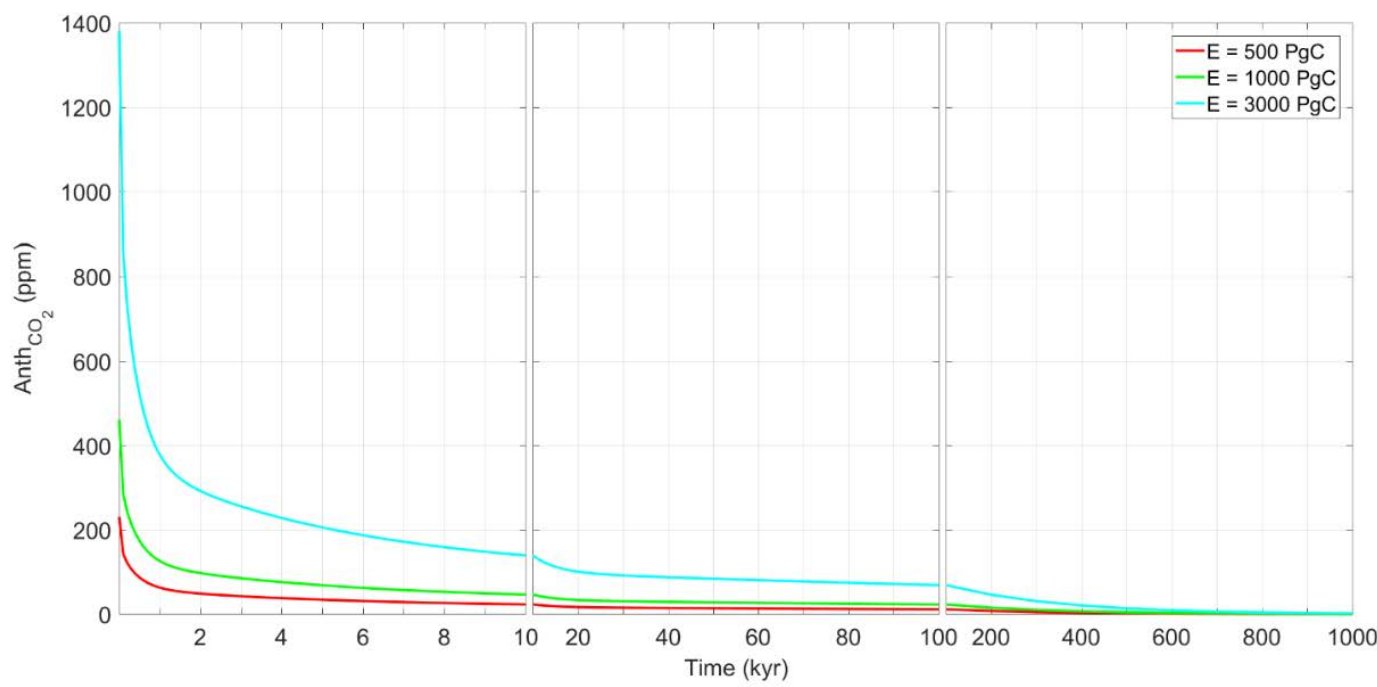

Figure 6: Anth $\mathrm{CO}_{2}(t)$ expressed in ppm, following Lord et al. (2016) for the three different emission scenarios considered.

\subsection{Forecast under natural scenario}

Figure 7a displays the natural scenario probabilistic forecast for ice volume. The forecast indicates both periods of high agreement and periods of high discrepancy between solutions, highlighting the co-existence of more certain (deterministic) and lesss certain aspects of the Earth system response to orbital forcing. Most of the solutions agree that the planet will remain 
in a long interglacial state for the next $50 \mathrm{kyr}$, during which no large ice-growth is expected. This behaviour is predefined by one of the model constrains, namely, that $\mathrm{v}$ should be equal zero at present and by a low orbital forcing during the next 50 kyr. With high level of confidence, a second long interglacial is expected to occur between 450 and $500 \mathrm{kyr}$, which is another prolonged period of low orbital forcing related to 400 kyr periodicity of eccentricity. Also with high certainty, short ( 10 kyr) interglacials are expected to occur in 110, 230, 250, 270, 370, 620, 820 and $900 \mathrm{kyr}$ from present. Regarding the timing of the next full glacial conditions (defined here as the first moment after present in which ice volume reaches 0.5 in normalized units) the solutions tend to cluster into two different possibilities: predicted to occur in $\sim 90 \mathrm{kyr}$ or in $\sim 150 \mathrm{kyr}$ (see also Fig. 3). For those cases, the ice-growth begins at $\sim 50 \mathrm{kyr}$ or $\sim 110 \mathrm{kyr}$, respectively. There is also some level of certainty in the timing of occurrence of major glaciations (defined here as periods with ice volume higher than 0.8 in normalized units): in 100 kyr, $\sim 210 \mathrm{kyr}, \sim 410 \mathrm{kyr}, \sim 450 \mathrm{kyr}, \sim 680 \mathrm{kyr}, \sim 790 \mathrm{kyr}, \sim 870 \mathrm{kyr}$ and $950 \mathrm{kyr}$ from present. The forecast indicates that only two of these major glaciations (the ones in $\sim 210 \mathrm{kyr}$ and $\sim 870$ kyr after present) have high probability of reaching LGM magnitudes ( $\sim 1$ in normalized units).

If we consider the forecast produced by the trajectory of the Best Solution (Fig. 8) as the most likely path, under natural circumstances: 1. The next glacial inception is expected to occur $\sim 50 \mathrm{kyr}$ after present (with full glacial conditions reached 90 kyr after present); 2. In the next 1 Myr two long interglacials should take place; 3. Nine major glaciations are expected, all of them with maximum magnitudes around 10-15\% lower than LGM level. The natural glacial cycles of the future are strongly dominated by 100 kyr cyclicity as were the past ones.

\subsection{Forecast under anthropogenic $\mathrm{CO}_{2}$ emissions scenarios}

The evolution of the ice volume in the low-emissions anthropogenic scenario ( $\mathrm{E}=500 \mathrm{PgC}$ ) is forecasted to be significantly different from the natural one in the next $200 \mathrm{kyr}$, indicating a long-lasting impact of fossil-fuel $\mathrm{CO}_{2}$ releases (Fig. 7b). The uncertainty levels for the next $150 \mathrm{kyr}$ and from 400 to $500 \mathrm{kyr}$ are greatly reduced, with most of the solutions agreeing on icefree NH conditions (excepting Greenland). Under this scenario, only after half a million years is the Earth system able to return to an evolution similar to the one expected under natural conditions. Under this setting, the next full glacial conditions are not expected to be able to occur before $180 \mathrm{kyr}$ from present, implying a delay of at least $90 \mathrm{kyr}$ from the natural expected evolution which is consistent with Archer and Ganopolski (2005) and Ganopolski et al. (2016). In particular, the ice volume evolution of the Best Solution under this scenario differs significantly from the natural one during two periods: [0 kyr, $200 \mathrm{kyr}]$ and [400 kyr, $500 \mathrm{kyr}$ ]. In both time spans glaciations fail to be triggered for this scenario (Figs. 7b and 8a). In [200 kyr, 350 kyr] the low-emissions Best Solution trajectory is similar to the natural one, except for a lag of $\sim 10 \mathrm{kyr}$. $\mathrm{CO}_{2}$ and global mean surface temperature anomalies (Figs. 8b and 8c) pathways are also restored to natural conditions only after 500 kyr from present.

For the intermediate-emissions case $(\mathrm{E}=1000 \mathrm{PgC})$ the effect on the Earth system is even more notorious and long-lasting. The probabilistic forecast indicates significantly different conditions from the natural ones in the whole next half million years, 
with very low probability of considerable ice growth during the totality of this time span (Fig. 7c). In most of the solutions the full glacial conditions occur for the first time either in $~ 550 \mathrm{kyr}$ or between 600 and $700 \mathrm{kyr}$ from present (Fig. 3). In particular, the Best Solution is part of the latter group, with the next full glacial condition taking place only at $~ 670$ kyr after present.

Finally, with a cumulative pulse emission of $3000 \mathrm{PgC}$, the Earth system is expected, with high confidence, to experience almost ice-free conditions for the next $600 \mathrm{kyr}$ (Fig. 7d). Under this scenario, the next full glacial conditions are not expected to occur before $670 \mathrm{kyr}$ from present, implying a lag of almost $600 \mathrm{kyr}$ from the natural scenario. For example, in the Best Solution, only two major glaciations are predicted, peaking in $880 \mathrm{kyr}$ and with a magnitude 20\% lower than LGM (Figs. 7d and 8a). In the $3000 \mathrm{PgC}$ scenario, half a million years into the future, the $\mathrm{CO}_{2}$ is expected to be $300 \mathrm{ppm}$ (22 ppm higher than preindustrial levels) and the global mean surface temperature still $0.5^{\circ} \mathrm{C}$ higher than preindustrial level (Figs. 8b and $8 \mathrm{c}$ ).

\section{$5 \quad$ Summary and conclusions}

We propose a reduced-complexity process-based model of the evolution of global ice volume, atmospheric $\mathrm{CO}_{2}$ concentration and global mean temperature at multimillennial and orbital timescales. The model only external forcings are the orbital forcing and (for the future) anthropogenic $\mathrm{CO}_{2}$ cumulative emissions. The model consists of a system of three coupled non-linear differential equations representing physical mechanisms relevant for the evolution of the Climate - Ice Sheets - Carbon cycle System in timescales longer than thousands of years. Model parameters are selected to guarantee the best possible agreement with reconstructed ice volume variations during past 800 kyr. Global temperature anomaly at the Last Glacial Maximum and the current best estimate for the equilibrium climate sensitivity have been used as additional constraints on model parameters. Furthermore, the solutions are bounded to account for the difference between pre- and post- mid-Brühnes transition interglacial conditions and a minimum for $\mathrm{CO}_{2}$ concentration is set to avoid unrealistic solutions.

The model is successful in reproducing the natural glacial-interglacial cycles of the last $800 \mathrm{kyr}$, in agreement with paleorecords, replicating both the timing and amplitude of the major fluctuations, with a correlation between modelled and reconstructed global ice volume of up to 0.86 . The model also shows a promising performance when evaluated against data not used for training, indicating a certain skill in predictive mode.

Using different model realizations we generate a probabilistic forecast of the evolution of the system over the next one million years under natural and three different anthropogenic $\mathrm{CO}_{2}$ release scenarios. 
https://doi.org/10.5194/esd-2021-2

Preprint. Discussion started: 1 March 2021

(c) Author(s) 2021. CC BY 4.0 License.
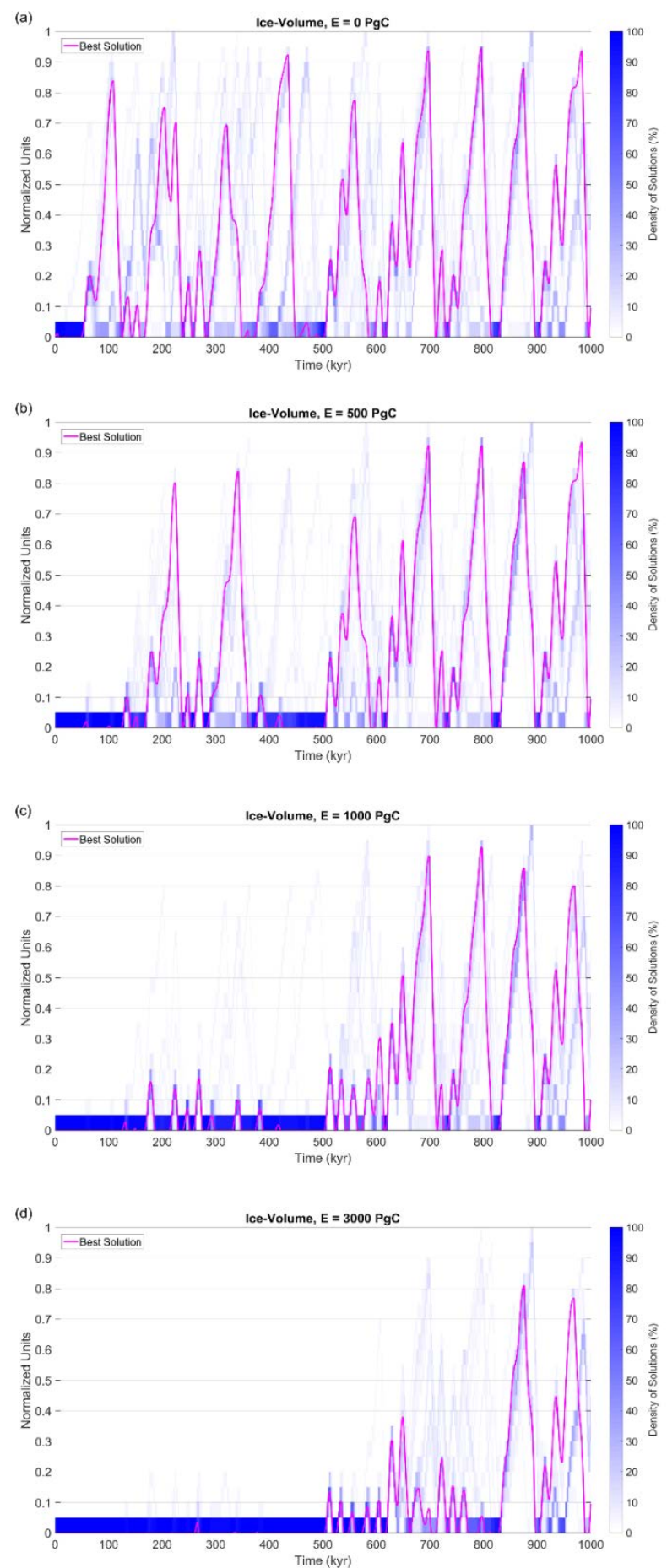

Figure 7: Probabilistic forecast (using the solutions in Accepted) for future NH landmass ice volume except Greenland (normalized to unity). a. Natural scenario. b. Low-emissions scenario $(E=500$ PgC). c. Intermediate-emissions scenario $(E=1000$ PgC) and d. High-emissions scenario $(\mathrm{E}=3000 \mathrm{PgC}$ ). The magenta line depicts the behaviour of the Best Solution, for each scenario. 
https://doi.org/10.5194/esd-2021-2

Preprint. Discussion started: 1 March 2021

(c) Author(s) 2021. CC BY 4.0 License.
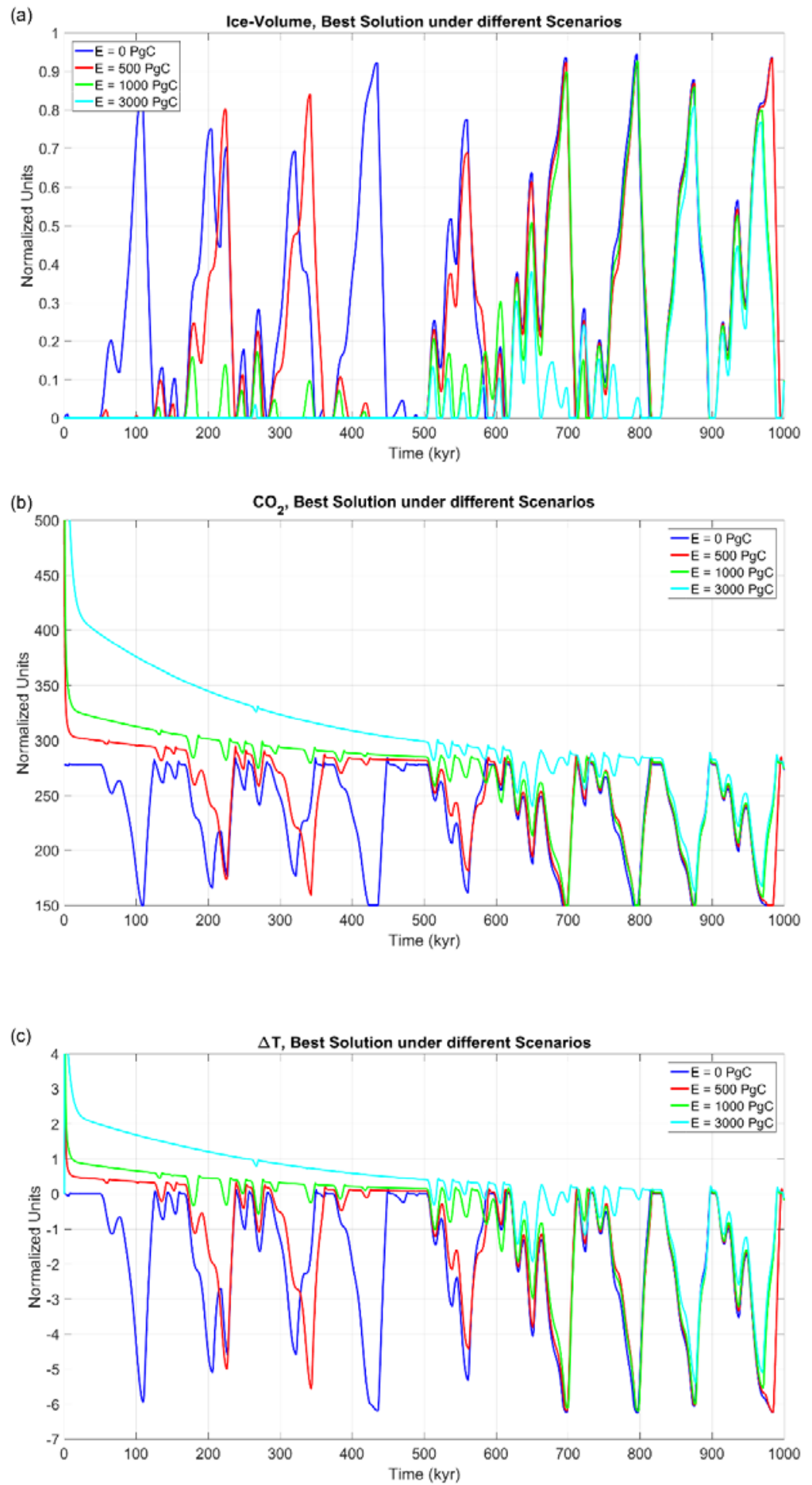

525 Figure 8: Forecast using the Best Solution for the next 1 Myr, under different emission scenarios: a. Ice volume (normalized to unity), b. $\mathrm{CO}_{2}$ (ppm), c. Global mean surface temperature anomalies (C). 
In the natural scenario, in which anthropogenic $\mathrm{CO}_{2}$ emissions are assumed to be zero at all times, the model assigns high probability of occurrence of: 1 . Long interglacials in two periods: [0 kyr, $120 \mathrm{kyr}$ ] and [400 kyr, $500 \mathrm{kyr}$ ] and 2. The next glacial inception will most likely occur $\sim 50 \mathrm{kyr}$ after present with the development of full glacial conditions $\sim 90 \mathrm{kyr}$ after present. It is also clear, however, that even though there is a high level of agreement in the solutions' trajectories during the past $800 \mathrm{kyr}$, their paths tend to diverge for the future indicating that the past does not perfectly constraint the future evolution of the climate - ice sheets - Carbon cycle system.

The selected model versions exhibit a large sensitivity to fossil-fuel $\mathrm{CO}_{2}$ releases, with even already achieved emissions (500 $\mathrm{PgC}$ ) causing a behaviour significantly different from the natural one over extremely long periods of time. The model predicts that a fossil-fuel $\mathrm{CO}_{2}$ release of $500 \mathrm{PgC}$ will make the beginning of the next Ice Age highly unlikely in the next $120 \mathrm{kyr}$ and a delay of half a million years is a possibility that cannot be ruled out. Cumulative fossil-fuel $\mathrm{CO}_{2}$ emissions of the order of 3000 PgC (which could be achieved in the next two to three centuries if humanity does not constraint fossil-fuel usage; Meinshausen et al., 2011) will most likely lead to ice-free conditions over the NH landmasses throughout the next half million

540 years. Under this scenario, the probability for the next glacial inception to occur before $600 \mathrm{kyr}$ is extremely low. Thus our study demonstrates that, in spite of large unecrtainties in model parameters, there is a qualitative difference in the long-term Earth system trajectories (Steffen et al., 2018) between cumulative emissions of 500 and 3000 GtC.

The present study reveals one serious challenge in modeling of the deep future: the results show very strong sensitivity to the relationship between critical insolation threshold for glacial inception and $\mathrm{CO}_{2}$ levels. In turn, this relationship is poorly constrained by the paleoclimatic data because during previous interglacials $\mathrm{CO}_{2}$ was close to or lower than the preindustrial level. So far, this relationship has been analysed only with the CLIMBER-2 model (Calov and Ganopolski, 2005; Ganopolski et al., 2016). This is why in this work, we assumed the uncertainty in this relationship of $100 \%$. Reducing this uncertainty by performing experiments similar to those described in Ganopolski et al. (2016) but with more advanced Earth system models can help to reduce uncertainties in future projections.

\section{Appendix A: Estimation of predictive skill}

555 When a model is developed with a predictive goal (like in this study), it is important to have an assessment of its predictive skill. The best possible estimations of this skill are obtained by evaluating how well the model performs when presented with previously unseen data.

To follow the cross-validation assessment criterion (Stone, 1974), we divide the period [-800 kyr, 0 kyr $]$ in halves: P1 = [-800 ky, $-400 \mathrm{kyr}]$ and P2 = [-400 kyr, 0 kyr]. First, P1 is labelled training set and P2 validation set. Second, the model is trained 
using the information in P1: we run the Optimisation scheme to maximise the correlation between modelled and paleo ice volume during P1; we then accept all the models (parameter combinations) yielding correlations higher than 0.7. Third, all the accepted models are validated using the information in P2. We select three different performance metrics: the correlation between modelled and paleo ice volume, between modelled and paleo $\mathrm{CO}_{2}$ or between modelled and global mean surface temperature anomaly, calculated during P2. Finally, we repeat the previous three steps but labelling P1 as validation and P2 as training sets, respectively. For each metric, the average that the models achieve on the two possible validation sets considered is the estimate of the model's predictive skill.

In Table A1 we summarize the results of this cross-validation assessment, showing the results for the three performance metrics. For reference, Table A1 also displays the values of the metrics when calculated over the training period (instead over the validation period). Results are the average of two possible cases: P1 as training and P2 as validation sets, or P2 as training and P1 as validation sets. As expected, when the same period is used both for model training and evaluation the results are in better agreement with paleoclimate data: the ice volume metric is 0.78 , the $\mathrm{CO}_{2}$-metric 0.52 and the temperature-metric 0.58 . These values drop to $0.49,0.36$ and 0.34 respectively, when the independent validation set is used to calculate the metrics. Even though the drop in performance is not negligible, the model skill is still substantial in particular for predicting ice volume.

Table A1: Estimation of Model Predictive Skill. Only solutions leading to a correlation between modelled and paleo estimation of ice volume higher than $\mathbf{0 . 7}$, calculated over the training period, are considered. Please see text for more details on the training and validation periods used.

\begin{tabular}{|c|c|c|}
\hline $\begin{array}{c}\text { Ensemble-Mean Correlations Between } \\
\text { Modelled and Paleo-data }\end{array}$ & Calculated over the Learning period & $\begin{array}{c}\text { Calculated over an independent } \\
\text { validation period }\end{array}$ \\
\hline Ice volume & 0.78 & 0.49 \\
\hline $\mathrm{CO}_{2}$ & 0.52 & 0.36 \\
\hline Temperature & 0.58 & 0.34 \\
\hline
\end{tabular}

\section{Code/Data availability}

Code and data used in this study can be obtained from: https://doi.org/10.17605/OSF.IO/KB76G (Talento, 2021).

\section{Author contribution}

AG conceived the original idea. ST performed all the calculations and produced figures. Both authors contributed to the analysis of results and writing of the manuscript. 
https://doi.org/10.5194/esd-2021-2

Preprint. Discussion started: 1 March 2021

(c) Author(s) 2021. CC BY 4.0 License.

(c) (i)

\section{Competing interests}

590 The authors declare that they have no conflict of interest.

\section{Acknowledgments}

Financial support for this study was provided by the Swiss National Cooperative for the Disposal of Radioactive Waste (NAGRA).

595

\section{References}

Abe-Ouchi, A., Saito, F., Kawamura, K., Raymo, M. E., Okuno, J., Takahashi, K. and Blatter, H.: Insolation-driven 100,000year glacial cycles and hysteresis of ice-sheet volume, Nature, 500(7461), 190-193, https://doi.org/10.1038/nature12374, 6002013.

Annan, J.D. and Hargreaves, J.C.: A new global reconstruction of temperature changes at the Last Glacial Maximum.Clim. Past, 9, 367-376, https://doi.org/10.5194/cp-9-367-2013, 2013.

605 Archer, D. and Brovkin, V.: The millennial atmospheric lifetime of anthropogenic CO2, Climatic Change, 90(3), 283-297, https://doi.org/10.1007/s10584-008-9413-1, 2008.

Archer, D. and Ganopolski, A.: A movable trigger: Fossil fuel $\mathrm{CO}_{2}$ and the onset of the next glaciation: Next Glaciation, Geochem. Geophys. Geosyst., 6(5), n/a-n/a, https://doi.org/10.1029/2004GC000891, 2005.

610

Archer, D., Kheshgi, H. and Maier-Reimer, E.: Multiple timescales for neutralization of fossil fuel $\mathrm{CO}_{2}$, Geophys. Res. Lett., 24(4), 405-408, https://doi.org/10.1029/97GL00168, 1997.

Armour, K. C.: Energy budget constraints on climate sensitivity in light of inconstant climate feedbacks, Nature Clim Change, 615 7(5), 331-335, https://doi.org/10.1038/nclimate3278, 2017.

Berger, A.: Climat: An Exceptionally Long Interglacial Ahead?, Science, 297(5585), 1287-1288, https://doi.org/10.1126/science.1076120, 2002. 
https://doi.org/10.5194/esd-2021-2

Preprint. Discussion started: 1 March 2021

(c) Author(s) 2021. CC BY 4.0 License.

(c) (i)

620 Brovkin, V., Ganopolski, A., Archer, D. and Rahmstorf, S.: Lowering of glacial atmospheric $\mathrm{CO}_{2}$ in response to changes in oceanic circulation and marine biogeochemistry: Mechanisms of lowering glacial pCO2, Paleoceanography, 22(4), n/a-n/a, https://doi.org/10.1029/2006PA001380, 2007.

Brovkin, V., Ganopolski, A., Archer, D. and Munhoven, G.: Glacial CO2 cycle as a succession of key physical and biogeochemical processes, Clim. Past, 8(1), 251-264, https://doi.org/10.5194/cp-8-251-2012, 2012.

Calov, R. and Ganopolski, A.: Multistability and hysteresis in the climate-cryosphere system under orbital forcing, Geophys. Res. Lett., 32(21), L21717, https://doi.org/10.1029/2005GL024518, 2005.

630 Cochelin, A.-S. B., Mysak, L. A. and Wang, Z.: Simulation of long-term future climate changes with the green McGill paleoclimate model: the next glacial inception, Climatic Change, 79(3-4), 381-401, https://doi.org/10.1007/s10584-006-9099$1,2006$.

Crucifix, M.: Oscillators and relaxation phenomena in Pleistocene climate theory, Phil. Trans. R. Soc. A., 370(1962), 1140635 1165, https://doi.org/10.1098/rsta.2011.0315, 2012.

Crucifix, M.: Why could ice ages be unpredictable? Clim. Past, 9(5), 2253-2267, https://doi.org/10.5194/cp-9-2253-2013, 2013.

640 Eby, M., Zickfeld, K., Montenegro, A., Archer, D., Meissner, K. J. and Weaver, A. J.: Lifetime of Anthropogenic Climate Change: Millennial Time Scales of Potential CO2 and Surface Temperature Perturbations, Journal of Climate, 22(10), 25012511, https://doi.org/10.1175/2008JCLI2554.1, 2009.

Friedrich, T., Timmermann, A., Tigchelaar, M., Elison Timm, O. and Ganopolski, A.: Nonlinear climate sensitivity and its 645 implications for future greenhouse warming, Sci. Adv., 2(11), e1501923, https://doi.org/10.1126/sciadv.1501923, 2016.

Ganopolski, A.: Towards Generalized Milankovitch Theory. To be submitted to Climate of the Past, 2021.

Ganopolski, A. and Brovkin, V.: Simulation of climate, ice sheets and CO2 evolution during the last four glacial cycles with 650 an Earth system model of intermediate complexity, Clim. Past, 13(12), 1695-1716, https://doi.org/10.5194/cp-13-1695-2017, 2017. 
https://doi.org/10.5194/esd-2021-2

Preprint. Discussion started: 1 March 2021

(c) Author(s) 2021. CC BY 4.0 License.

Ganopolski, A. and Calov, R.: The role of orbital forcing, carbon dioxide and regolith in 100 kyr glacial cycles, Clim. Past, 7(4), 1415-1425, https://doi.org/10.5194/cp-7-1415-2011, 2011.

655

Ganopolski, A., Calov, R. and Claussen, M.: Simulation of the last glacial cycle with a coupled climate ice-sheet model of intermediate complexity, Clim. Past, 16, 2010.

Ganopolski, A., Winkelmann, R. and Schellnhuber, H. J.: Critical insolation-CO2 relation for diagnosing past and future glacial inception, Nature, 529(7585), 200-203, https://doi.org/10.1038/nature16494, 2016.

Gottschalk, J., Battaglia, G., Fischer, H., Frölicher, T. L., Jaccard, S. L., Jeltsch-Thömmes, A., Joos, F., Köhler, P., Meissner, K. J., Menviel, L., Nehrbass-Ahles, C., Schmitt, J., Schmittner, A., Skinner, L. C. and Stocker, T. F.: Mechanisms of millennialscale atmospheric CO2 change in numerical model simulations, Quaternary Science Reviews, 220, 30-74, https://doi.org/10.1016/j.quascirev.2019.05.013, 2019.

Hays, J. D., Imbrie, J. and Shackleton, N. J.: Variations in the Earth’s Orbit: Pacemaker of the Ice Ages, Science, 194(4270), 1121-1132, https://doi.org/10.1126/science.194.4270.1121, 1976.

Imbrie, J., and Imbrie, J.: Modeling the climatic response to orbital variations, Science, 207, https://doi.org/10.1126/science.207.4434.943, 1980.

International Atomic Energy Agency: Spent Fuel and High Level Waste: Chemical Durability and Performance under Simulated Repository Conditions, 2007.

675

Kim, J.-S., Kwon, S.-K., Sanchez, M. and Cho, G.-C.: Geological storage of high level nuclear waste, KSCE J Civ Eng, 15(4), 721-737, https://doi.org/10.1007/s12205-011-0012-8, 2011.

Kobayashi, H., Abe-Ouchi, A. and Oka, A.: Role of Southern Ocean stratification in glacial atmospheric $\mathrm{CO}_{2}$ reduction 680 evaluated by a three-dimensional ocean general circulation model: $\mathrm{CO}_{2}$ Response to Glacial Stratification, Paleoceanography, 30(9), 1202-1216, https://doi.org/10.1002/2015PA002786, 2015.

Laskar, J., Robutel, P., Joutel, F., Gastineau, M., Correia, A. C. M. and Levrard, B.: A long-term numerical solution for the insolation quantities of the Earth, A\&A, 428(1), 261-285, https://doi.org/10.1051/0004-6361:20041335, 2004. 
Laws, E. A., Falkowski, P. G., Smith, W. O., Ducklow, H. and McCarthy, J. J.: Temperature effects on export production in the open ocean, Global Biogeochem. Cycles, 14(4), 1231-1246, https://doi.org/10.1029/1999GB001229, 2000.

Le Quéré, C., Andrew, R. M., Friedlingstein, P., Sitch, S., Hauck, J., Pongratz, J., Pickers, P. A., Korsbakken, J. I., Peters, G.

P., Canadell, J. G., Arneth, A., Arora, V. K., Barbero, L., Bastos, A., Bopp, L., Chevallier, F., Chini, L. P., Ciais, P., Doney, S. C., Gkritzalis, T., Goll, D. S., Harris, I., Haverd, V., Hoffman, F. M., Hoppema, M., Houghton, R. A., Hurtt, G., Ilyina, T., Jain, A. K., Johannessen, T., Jones, C. D., Kato, E., Keeling, R. F., Goldewijk, K. K., Landschützer, P., Lefèvre, N., Lienert, S., Liu, Z., Lombardozzi, D., Metzl, N., Munro, D. R., Nabel, J. E. M. S., Nakaoka, S., Neill, C., Olsen, A., Ono, T., Patra, P., Peregon, A., Peters, W., Peylin, P., Pfeil, B., Pierrot, D., Poulter, B., Rehder, G., Resplandy, L., Robertson, E., Rocher, M.,

695 Rödenbeck, C., Schuster, U., Schwinger, J., Séférian, R., Skjelvan, I., Steinhoff, T., Sutton, A., Tans, P. P., Tian, H., Tilbrook, B., Tubiello, F. N., van der Laan-Luijkx, I. T., van der Werf, G. R., Viovy, N., Walker, A. P., Wiltshire, A. J., Wright, R., Zaehle, S. and Zheng, B.: Global Carbon Budget 2018, Earth Syst. Sci. Data, 10(4), 2141-2194, https://doi.org/10.5194/essd10-2141-2018, 2018.

700 Lenton, T. M. and Britton, C.: Enhanced carbonate and silicate weathering accelerates recovery from fossil fuel $\mathrm{CO}_{2}$ perturbations: Weathering accelerates removal of fossil fuel CO2, Global Biogeochem. Cycles, 20(3), n/a-n/a, https://doi.org/10.1029/2005GB002678, 2006.

Lenton, T. M., Marsh, R., Price, A. R., Lunt, D. J., Aksenov, Y., Annan, J. D., Cooper-Chadwick, T., Cox, S. J., Edwards, N. 705 R., Goswami, S., Hargreaves, J. C., Harris, P. P., Jiao, Z., Livina, V. N., Payne, A. J., Rutt, I. C., Shepherd, J. G., Valdes, P. J., Williams, G., Williamson, M. S. and Yool, A.: Effects of atmospheric dynamics and ocean resolution on bi-stability of the thermohaline circulation examined using the Grid ENabled Integrated Earth system modelling (GENIE) framework, Clim Dyn, 29(6), 591-613, https://doi.org/10.1007/s00382-007-0254-9, 2007.

710 Lisiecki, L. E. and Raymo, M. E.: A Pliocene-Pleistocene stack of 57 globally distributed benthic $\delta{ }^{18}$ O records: PliocenePleistocene Benthic Stack, Paleoceanography, 20(1), n/a-n/a, https://doi.org/10.1029/2004PA001071, 2005.

Lord, N. S., Ridgwell, A., Thorne, M. C. and Lunt, D. J.: An impulse response function for the "long tail” of excess atmospheric $\mathrm{CO}_{2}$ in an Earth system model, Global Biogeochem. Cycles, 30(1), 2-17, https://doi.org/10.1002/2014GB005074, 2016.

Lüthi, D., Le Floch, M., Bereiter, B., Blunier, T., Barnola, J.-M., Siegenthaler, U., Raynaud, D., Jouzel, J., Fischer, H., Kawamura, K. and Stocker, T. F.: High-resolution carbon dioxide concentration record 650,000-800,000 years before present, Nature, 453(7193), 379-382, https://doi.org/10.1038/nature06949, 2008. 
https://doi.org/10.5194/esd-2021-2

Preprint. Discussion started: 1 March 2021

(c) Author(s) 2021. CC BY 4.0 License.

(c) (1)

720 Martin, J. H.: Glacial-interglacial CO 2 change: The Iron Hypothesis, Paleoceanography, 5(1), 1-13, https://doi.org/10.1029/PA005i001p00001, 1990.

McGlade, C. and Ekins, P.: The geographical distribution of fossil fuels unused when limiting global warming to $2{ }^{\circ} \mathrm{C}$, Nature, 517(7533), 187-190, https://doi.org/10.1038/nature14016, 2015.

Meinshausen, M., Smith, S. J., Calvin, K., Daniel, J. S., Kainuma, M. L. T., Lamarque, J.-F., Matsumoto, K., Montzka, S. A., Raper, S. C. B., Riahi, K., Thomson, A., Velders, G. J. M. and van Vuuren, D. P. P.: The RCP greenhouse gas concentrations and their extensions from 1765 to 2300, Climatic Change, 109(1-2), 213-241, https://doi.org/10.1007/s10584-011-0156-z, 2011.

Menviel, L., Joos, F. and Ritz, S.P.: Simulating atmospheric CO2, 13C and the marine carbon cycle during the Last GlacialInterglacial cycle: possible role for a deepening of the mean remineralization depth and an increase in the oceanic nutrient inventory. Quaternary Science Reviews, 56, 46-68, https://doi.org/10.1016/j.quascirev.2012.09.012, 2012.

Milankovitch, M., Kanon der Erdbestrahlung und Seine Andwendung auf das Eiszeitenproblem, vol. 33, 633 pp., R. Serbian Acad. Spec. Publ. 132, Belgrade, 1941.

Paillard, D.: The timing of Pleistocene glaciations from a simple multiple-state climate model, Nature, 391(6665), 378-381, https://doi.org/10.1038/34891, 1998.

Paillard, D. and Parrenin, F.: The Antarctic ice sheet and the triggering of deglaciations, Earth and Planetary Science Letters, 227(3-4), 263-271, https://doi.org/10.1016/j.epsl.2004.08.023, 2004.

Petit, J. R., Jouzel, J., Raynaud, D., Barkov, N. I., Barnola, J.-M., Basile, I., Bender, M., Chappellaz, J., Davis, M., Delaygue, 745 G., Delmotte, M., Kotlyakov, V. M., Legrand, M., Lipenkov, V. Y., Lorius, C., PÉpin, L., Ritz, C., Saltzman, E. and Stievenard, M.: Climate and atmospheric history of the past 420,000 years from the Vostok ice core, Antarctica, Nature, 399(6735), 429436, https://doi.org/10.1038/20859, 1999.

Pollard, D.: A coupled climate-ice sheet model applied to the Quaternary Ice Ages, J. Geophys. Res., 88(C12), 7705, https://doi.org/10.1029/JC088iC12p07705, 1983. 
https://doi.org/10.5194/esd-2021-2

Preprint. Discussion started: 1 March 2021

(c) Author(s) 2021. CC BY 4.0 License.

Prentice, I. C., Meng, T., Wang, H., Harrison, S. P., Ni, J. and Wang, G.: Evidence of a universal scaling relationship for leaf CO2 drawdown along an aridity gradient, New Phytologist, 190(1), 169-180, https://doi.org/10.1111/j.14698137.2010.03579.x, 2011.

Ridgwell, A. and Hargreaves, J. C.: Regulation of atmospheric $\mathrm{CO}_{2}$ by deep-sea sediments in an Earth system model: Regulation of CO2 by deep -sea sediments, Global Biogeochem. Cycles, 21(2), n/a-n/a, https://doi.org/10.1029/2006GB002764, 2007.

Saltzman, B.: Carbon dioxide and the $\delta 18$ O record of late-Quaternary climatic change: a global model. Climate Dynamics, 1(2), 77-85, 1987.

Saltzman, B. and Verbitsky, M. Y.: Multiple instabilities and modes of glacial rhythmicity in the plio-Pleistocene: a general theory of late Cenozoic climatic change, Climate Dynamics, 9(1), 1-15, https://doi.org/10.1007/BF00208010, 1993.

Schneider von Deimling, T., Ganopolski, A., Held, H. and Rahmstorf, S.: How cold was the last glacial maximum?. Geophysical Research Letters, 33(14), https://doi.org/10.1029/2006GL026484, 2006.

Snyder, C. W.: Evolution of global temperature over the past two million years, Nature, 538(7624), 226-228, https://doi.org/10.1038/nature19798, 2016.

Spratt, R. M. and Lisiecki, L. E.: A Late Pleistocene sea level stack, Clim. Past, 12(4), 1079-1092, https://doi.org/10.5194/cp12-1079-2016, 2016.

775 Steffen, W., Rockström, J., Richardson, K., Lenton, T. M., Folke, C., Liverman, D., Summerhayes, C. P., Barnosky, A. D., Cornell, S. E., Crucifix, M., Donges, J. F., Fetzer, I., Lade, S. J., Scheffer, M., Winkelmann, R. and Schellnhuber, H. J.: Trajectories of the Earth System in the Anthropocene, Proc Natl Acad Sci USA, 115(33), 8252-8259, https://doi.org/10.1073/pnas.1810141115, 2018.

780 Stone, M.: Cross-Validatory Choice and Assessment of Statistical Predictions, Journal of the Royal Statistical Society: Series B (Methodological), 36(2), 111-133, https://doi.org/10.1111/j.2517-6161.1974.tb00994.x, 1974.

Tabor, C.R. and Poulsen, C.J.: Simulating the mid-Pleistocene transition through regolith removal. Earth and Planetary Science Letters, 434, 231-240, https://doi.org/10.1016/j.epsl.2015.11.034, 2016. 
https://doi.org/10.5194/esd-2021-2

Preprint. Discussion started: 1 March 2021

(c) Author(s) 2021. CC BY 4.0 License.

Talento, S.: Data: Evolution of the climate in the next Million years: A Reduced-Complexity Model for Glacial Cycles and Impact of anthropogenic $\mathrm{CO}_{2}$ emissions. https://doi.org/10.17605/OSF.IO/KB76G, 2021.

Tierney, J.E., Zhu, J., King, J., Malevich, S.B., Hakim, G.J. and Poulsen, C.J.: Glacial cooling and climate sensitivity revisited.

Nature, 584(7822), 569-573, https://doi.org/10.1038/s41586-020-2617-x, 2020.

Tzedakis, P. C., Raynaud, D., McManus, J. F., Berger, A., Brovkin, V. and Kiefer, T.: Interglacial diversity, Nature Geosci, 2(11), 751-755, https://doi.org/10.1038/ngeo660, 2009.

795 Tziperman, E., Raymo, M. E., Huybers, P. and Wunsch, C.: Consequences of pacing the Pleistocene 100 kyr ice ages by nonlinear phase locking to Milankovitch forcing: HOW TO PACE AN ICE AGE, Paleoceanography, 21(4), https://doi.org/10.1029/2005PA001241, 2006.

Watson, A. J., Bakker, D. C. E., Ridgwell, A. J., Boyd, P. W. and Law, C. S.: Effect of iron supply on Southern Ocean CO2 800 uptake and implications for glacial atmospheric CO2, Nature, 407(6805), 730-733, https://doi.org/10.1038/35037561, 2000.

Watson, A. J., Vallis, G. K. and Nikurashin, M.: Southern Ocean buoyancy forcing of ocean ventilation and glacial atmospheric CO2, Nature Geosci, 8(11), 861-864, https://doi.org/10.1038/ngeo2538, 2015.

805 Willeit, M., Ganopolski, A., Calov, R. and Brovkin, V.: Mid-Pleistocene transition in glacial cycles explained by declining $\mathrm{CO}_{2}$ and regolith removal, Sci. Adv., 5(4), eaav7337, https://doi.org/10.1126/sciadv.aav7337, 2019.

Zelinka, M. D., Myers, T. A., McCoy, D. T., Po-Chedley, S., Caldwell, P. M., Ceppi, P., Klein, S. A. and Taylor, K. E.: Causes of Higher Climate Sensitivity in CMIP6 Models, Geophys. Res. Lett., 47(1), https://doi.org/10.1029/2019GL085782, 2020. 